\title{
1. LA USANZA MORISCA: EL MODELO CULTURAL ISLÁMICO Y SU RECEPCIÓN EN LA CORTE REAL DE CASTILLA'
}

\author{
DAVID NOGALES RINCÓN
}

Universidad Autónoma de Madrid david.nogales@uam.es

\begin{abstract}
Resumen: La construcción de la imagen del poder regio en la Corona de Castilla no fue ajena a la influencia de la cultura islámica, articulada por la historiografía en torno al fenómeno conocido como mudejarismo. El presente artículo buscará realizar una aproximación a dicha problemática desde el punto de vista del estudio de los modelos culturales y de los procesos de recepción cultural en la corte real de Castilla. Dichos aspectos se estudiarán a través de la recepción de un conjunto de manifestaciones propias de la cultura islámica y andalusí, como los textiles, los rituales de exhibición del soberano y la arquitectura palatina, así como la reorientación que dichas expresiones experimentarán, en las décadas finales de la Edad Media, en el marco de la recepción del modelo tardogótico o borgoñón.
\end{abstract}

Palabras-clave: Corona de Castilla / Corte / Baja Edad Media / Islam / Mudejarismo / Realeza.

\section{LIKE THE MOORISH CUSTOM: THE ISLAMIC CULTURAL MODEL AND ITS RECEPTION IN THE ROYAL COURT OF CASTILE}

Abstract: The construction of the image of the royal power at the Crown of Castile was connected with the influence of the Islamic culture, articulated by historiography around the phenomenon known as mudejarismo. This paper aims to study this subject from the point of view of cultural models and cultural reception processes at the royal court of Castile. These processes of reception will be studied through the reception of certain characteristics belonging to the Islamic and Andalusí culture, as textiles, royal rituals or palatial architecture, and the reorientation process of these cultural expressions during the last decades of the Middle Ages in the framework of the reception of the Burgundian or Late Gothic model.

Key words: Crown of Castile / Court / Low Middle Ages / Islam / Mudejarismo / Kingship.

\section{Introducción}

La cultura islámica y, particularmente, la cultura andalusí constituyó la base parcial de las estrategias de representación del poder regio en la Corona de Castilla desde una perspectiva suntuaria, ritual y artística, articulada en torno al fenómeno conocido como mudejarismo. Esta manifestación, objeto preferente de atención por parte de la historiografía artística, es susceptible de ser estudiada, como otras realidades, desde la perspectiva de la teoría de los modelos culturales, ${ }^{2}$ siguiendo la estela de algunas aproximaciones a esta cuestión caracterizadas por su transversalidad. ${ }^{3}$ Desde un punto de vista metodológico, esta perspectiva fundamentada en la teoría de los modelos culturales permite: a) inte-

* Fecha de recepción: 15 de enero de 2018 / Fecha de aceptación: 26 de diciembre de 2018.

1 Este trabajo forma parte del Proyecto de I+D del Programa Estatal de Fomento de la Investigación Científica y Técnica de Excelencia, Subprograma Estatal de Generación de Conocimiento, HAR2016-76174-P Expresiones de la cultura política peninsular en las relaciones de conflicto (Corona de Castilla, 1230-1504) de la Secretaría de Estado de Investigación, Desarrollo e Innovación del Ministerio de Economía, Industria y Competitividad del Gobierno de España, dirigido por José Manuel Nieto Soria.

2 Una introducción general a estos en GONZÁLEZ BARROSO, Josué, 2012.

3 TORRES BALBÁS, Leopoldo, 1951, PÉREZ HIGUERA, Teresa, 1996, SILVA SANTA-CRUZ, Noelia, 2004 y SILVA SANTA-CRUZ, Noelia, 2005. 
grar y contextualizar informaciones diversas dentro de un modelo global explicativo; b) aproximarnos, desde una perspectiva cultural, al estudio de las estrategias de representación del poder y de las relaciones políticas; c) entender el papel que lo cultural tiene en la configuración de las identidades sociales y políticas medievales.

Desde este punto de vista de los modelos culturales, es interesante, como punto de parti$\mathrm{da}$, atender, en primer término, a los conceptos, definidos en el marco de la Historia cultural, de recepción creativa (creative reception) y de traducción cultural (cultural translation). ${ }^{4}$ Ambos conceptos remiten a la idea de que la transferencia cultural implica, por parte de la sociedad receptora, una actitud activa, basada en la descontextualización y recontextualización de informaciones, objetos o prácticas. Desde esta perspectiva, el análisis parte no tanto de cuestiones formales y estilísticas -aspectos, por otro lado, ya superados por la historiografía, gracias a las aportaciones de investigadores como Teresa Pérez Higuera, Juan Carlos Ruiz Souza, Noelia Silva Santa-Cruz, Rosa $\mathrm{M}^{\mathrm{a}}$ Rodríguez Porto, Elena Paulino Montero, $\mathrm{M}^{\mathrm{a}}$ Judith Feliciano o Cynthia Robinsoncomo de las inquietudes de las sociedades cristianas protagonistas de la recepción, a través de la incorporación al análisis de nociones como la tradición, las prácticas de consumo, las identidades o la intencionalidad de los promotores en la elección de una estética particular. En este sentido, esta orientación permite incidir, por ejemplo, en la existencia de marcos culturales compartidos entre las sociedades cristiana e islámica, en los intereses de la sociedad receptora cristiana, o en las nuevas funcionalidades que ocasionalmente artefactos, formas o fórmulas estéticas hubieron de asumir en dicha sociedad.

En segundo término, es interesante atender a algunas nociones ligadas a la denominada como historia cruzada (histoire croissé), y, dentro de esta, particularmente a la importancia concedida a lo que Michael Werner y Benedicte Zimmermann denominan como nivel transna- cional (transnational level) y a las interacciones múltiples entre centros, ${ }^{5}$ acorde a algunos de los postulados metodológicos de la Historia Global (Global History). ${ }^{6}$ Dicha perspectiva, aunque debe ser utilizada con prudencia para el período medieval, puede ayudar, no obstante, a entender algunos de estos fenómenos culturales dentro de amplios marcos espaciales, capaces de superar las divisiones habituales entre naciones, culturas o civilizaciones; orientación especialmente interesante, por ejemplo, a la hora de analizar cuestiones relativas al consumo de bienes de lujo. En este sentido, dicha perspectiva facilita la comprensión global de los procesos y proporciona -sin negar el peso fundamental y principal de los factores locales- marcos de análisis capaces de superar conceptos como la etnicidad o la confesionalidad. A su vez, permite poner de relieve el papel desempeñado por el contexto ibérico, en su condición de intermediador, en la transferencia de esta tradición islámica hacia otros espacios de la cristiandad. En suma, posibilita analizar estas transferencias culturales en su complejidad, insertas dentro de redes de interrelaciones amplias, en las que unas realidades actúan como espejo de otras, influyéndose mutuamente.

\section{La recepción del modelo cultural islámico en la corte real de Castilla. Algunas observaciones sobre el mudejarismo desde la perspectiva cultural}

El concepto cultural y artístico de mudéjar y estilo mudéjar ha sido una categoría ampliamente debatida en el ámbito de los estudios artísticos casi desde el momento mismo de su formulación, atribuida tradicionalmente a José Amador de los Ríos, quien recogió distintas reflexiones vertidas en la comisión artístico-arqueológica creada el 3 de julio de 1856, con la misión de publicar la obra Monumentos arquitectónicos de España, sintetizándolas en su famoso discurso de ingreso a la plaza de académico de la Real Academia de Bellas Artes de San Fernando, el 19 de junio de 1859, con el título de El estilo mudéjar en arquitectura. ${ }^{7}$ Aunque la aplicación de

${ }^{4}$ BURKE, Peter, 2000, pp. 15-21; BURKE, Peter, 2009

${ }^{5}$ WERNER, Michael; ZIMMERMANN, Benedicte, 2003, pp. 15, 22.

6 SACHSENMAIER, Dominic, 2011.

7 GARCÍA NISTAL, Joaquín, 2013. Las aproximaciones a esta cuestión son diversas, pudiendo destacarse, sin deseo de exhaustividad, los trabajos de URQUÍZAR HERRERA, Antonio, 2009-2010; BORRÁS GUALíS, Gonzalo, 2012; RUIZ SOUZA, Juan Carlos, 2009; RUIZ SOUZA, Juan Carlos, 2010; RUIZ SOUZA, Juan Carlos, 2016; GARCíA ALCÁZAR, Silvia, 2009, pp. 439-450; KUME, Junko, 2016; GÓMEZ GALÁN, José, 2017. 
una perspectiva cultural en el estudio del mudejarismo -algo que, por otro lado, no es una novedad- no resuelve esta compleja problemática, sí puede ayudar a poner el énfasis en los receptores y sus inquietudes -cuestión que, como señalábamos, no ha sido, en modo alguno, obviada por la historiografía-, más allá de los estilos artísticos, las formas o los materiales, que, sin duda, han ofrecido resultados fundamentales para entender esta realidad.

En continuidad con las líneas esbozadas por autores como Leopoldo Torres Balbás, Fernando Chueca Goitia o Teresa Pérez Higuera, ${ }^{8}$ desde la perspectiva aquí adoptada, lo mudéjar podría ser definido como la recepción y adaptación formal o funcional, por parte de las sociedades cristianas ibéricas medievales y modernas (y sus proyecciones americanas), de la cultura y tradición islámicas. Recepción y adaptación que no habría de suponer necesariamente la participación de mano de obra musulmana. Una definición que permite: a) superar la definición preferentemente artística de lo mudéjar, para aproximarse a este como una manifestación cultural global dentro de la sociedad castellana medieval; b) atender, en el estudio de este fenómeno, a la complejidad de la sociedad castellana y a sus problemáticas socio-políticas, más allá de etiquetas genéricas, como la maurofilia; c) incorporar otras categorías de análisis que permitan una aproximación real a los procesos culturales del pasado, superando categorías restrictivas, como el problemático estilo mudéjar y otras etiquetas subalternas, como el estilo Isabel o el estilo Cisneros, acuñados en el marco de la teoría de los estilos y desechados, en la actualidad, por los estudios artísticos, o el más impreciso hibridación; d) advertir sobre el factor creativo que implica dicho proceso de recepción, dando lugar a resultados diversos y, con frecuencia, nuevos, diferenciados y con entidad propia, desde el punto de vista de su estética, significado y/o función, con respecto a los modelos originales representados por el arte andalusí o hispano-musulmán. Ello permite establecer así distinciones entre el arte andalusí o islámico en sentido estricto y los productos de dicha recepción, al margen de la denominación o etiqueta que se les quiera dar, de su caracterización cultural (cristiana/islámica) o del intento de articular en torno a dichas expresiones un estilo artístico.

Junto a estos modos de aproximación a la recepción del modelo cultural andalusí en Castilla, aparece una segunda cuestión, ¿cómo denominar los resultados de dicha recepción? Pensamos que el adjetivo de mudéjar y el sustantivo mudejarismo -con todas las prevenciones y matizaciones necesarias, como las que han venido planteando diversos estudios durante los últimos años, con los trabajos de Ruiz Souza a la cabeza-, son términos útiles para referir de una forma cómoda una categoría bien asentada en la historiografía artística. Dicha categoría además remitiría, desde el punto de vista cultural y especialmente material, a una realidad con entidad propia dentro de la sociedad castellana bajomedieval, al menos, desde el siglo XIII, referida a través de la etiqueta morisco, entendida genéricamente como "cosa de moro", en palabras de Antonio de Nebrija. ${ }^{9}$ Esta denominación de mudéjar, en cualquier caso, se presenta como más adecuada que su correspondiente, en castellano medieval, morisco, que constituye una categoría más amplia desde el punto de vista de su caracterización cultural ${ }^{10}$ y que, además, en época moderna, como refiere Sebastián de Covarrubias, pasará a designar a "los convertidos de los moros a la fe católica". ${ }^{11}$

En realidad, el problema por delimitar esta realidad del mudejarismo y qué cabe considerar y qué no bajo la etiqueta de lo mudéjar es una cuestión que, aunque ha despertado cierto interés, por formar parte del debate sobre la identidad cultural española, es común a la propia definición y delimitación de toda cultura y tradición cultural. Ello se debe a que tanto la cultura como la tradición cultural no tienen, en verdad, una entidad real, sino que se trata de simples categorías mentales, con una dimensión simbólica, intangible y con frecuencia fluida, que permiten sistematizar culturalmente las distintas mues-

\footnotetext{
8 TORRES BALBÁS, Leopoldo, 1949, p. 238; CHUECA GOITIA, Fernando, 2001, pp. 466-467; PÉREZ HIGUERA, Teresa, 1987, p. 6.

${ }^{9}$ NEBRIJA, Antonio de, 1495, "Morisco", sin fol.

${ }^{10}$ Cf. RUIZ SOUZA, Juan Carlos, 2004, p. 38; RUIZ SOUZA, Juan Carlos, 2010, p. 194; CÓRDOBA DE LA LLAVE, Ricardo, 1988, pp. 587-589.

11 COVARRUBIAS, Sebastián de, 1611, p. 556.
} 
tras tangibles existentes (un edificio, un tejido, etc.), es decir, aquello que, a grandes rasgos, cabría identificar con lo que desde la filosofía François Jullien designa como recursos culturales y desde la antropología o la sociología se conoce como artefacto cultural. ${ }^{12}$ Este hecho genera que los límites de la cultura y de la tradición cultural no siempre sean claros, pues dependen, en buena medida, de las identidades culturales particulares a partir de las cuales se definen y delimitan ambas nociones. ${ }^{13}$

En este sentido, se trata de una tarea fundamental -con el objeto de que la categoría adoptada sea lo más precisa posible en la aproximación cultural al pasado histórico-, diferenciar entre los orígenes reales y las relecturas identitarias que han hecho las sociedades del pasado y presente, ${ }^{14}$ al asignar un origen cultural a tal o cual realidad en función de sus intereses y querencias.

\section{Caracterización y etapas en la recepción del modelo cultural islámico en la Corona de Castilla: perspectivas desde la corte real castellano-leonesa}

La recepción del modelo cultural islámico por parte de la cúspide del poder político castellano fue el resultado de un lento proceso de asimilación, que se puede retrotraer, al menos, al siglo $X$. En la incorporación de este modelo andalusí, la corte castellana adoptó, en unos casos, pautas novedosas con respecto a otras monarquías europeas ( $v$. gr. las plantas centralizadas incorporadas a la arquitectura palatina y religiosa). En otros casos, no hacía sino seguir gustos más amplios compartidos por otras cortes reales, nobiliarias o episcopales del Occidente medieval ( $v$. gr. el consumo textil). Y, en otros supuestos, la adopción de pautas andalusíes constituyó una respuesta local a inquietudes comunes a las cortes de la Europa medieval (v. gr. la incorporación a la arquitectura palatina caste- llana de la sala oblonga de origen andalusí con una función equiparable a los halls ingleses o a las grandes salles francesas; la adopción de los juegos de cañas, a modo de versión local de los juegos caballerescos comunes a la cristiandad; o la definición de un gusto por la magnificencia en torno a un modelo suntuario de origen andalusí, como eran los arreos y jaeces de la gineta y la moda a la morisca). Modalidades de recepción que serían, en definitiva, muestra de las complejas motivaciones y modos de traducción cultural, a medio camino entre lo local y lo global.

En esta recepción desde la perspectiva cortesana, se podrían fijar dos ámbitos fundamentales: el campo literario, que ofrecería un modelo de saber ligado al ejercicio del poder, explotado especialmente por Alfonso $X$ de Castilla (1252-1284), en torno a lo que Francisco Márquez Villanueva ha denominado como el "concepto cultural alfonsí". ${ }^{15} \mathrm{Y}$ el campo material, entendido en su sentido más amplio (arquitectura, ajuar doméstico, vestido, etc.), sobre el que centraremos nuestro trabajo desde la perspectiva particular de la corte real de Castilla, en la que se contemplará igualmente su entorno aristocrático. En este campo, dicho modelo proporcionó, ante todo, un conjunto de formulaciones visuales -con derivaciones tanto estéticas como simbólicas- adecuadas para la construcción de la imagen ritual del monarca y por extensión de su nobleza, en torno a dos conceptos: las percepciones autoritarias del poder y la expresión de la magnificencia. ${ }^{16}$

No obstante, con un carácter más específico, cabría atender, junto a este interés por la proyección de las imágenes autoritarias y magnificentes del poder, a otras cuestiones secundarias. En primer lugar, las identidades sociales y políticas. En este sentido, sería posible observar, al menos, desde inicios del siglo XV, el carácter emblemático que tendrían

\footnotetext{
12 JULLIEN, François, 2017, p. 69; ISAVA, 2009.

13 Sobre esta cuestión, véase GIMÉNEZ, Gilberto, 2003.

${ }_{14}$ Algunas cuestiones al respecto, a modo de ejemplo, se pueden ver en CÓRDOBA DE LA LLAVE, Ricardo, 1988, pp. 587-588.

15 MÁRQUEZ VILLANUEVA, Francisco, 2004.

${ }^{16}$ Este aspecto ha sido estudiado, para el ámbito de la realeza normanda en Sicilia, en relación con la recepción de elementos bizantinos e islámicos, sobre los cuales ha señalado Karen C. Britt que "by incorporating themes and artistic trends of rule in Islam and Byzantium, he [Roger II] claimed the authority that these symbols represented" (BRITT, Karen C., 2007, p. 34), a la vez que Oleg Grabar ha señalado que este monarca adoptaría pautas artísticas islámicas atendiendo "only the ideological or aesthetic effect they have" (GRABAR, Oleg, 2006a, p. 50).
} 
ciertos regalos diplomáticos de origen morisco enviados por el rey de Castilla a otras cortes extranjeras, como los "muchos cueros de guadamecir e muchas alhombras" remitidos en 1411 al rey francés por Juan II de Castilla (1406-1454) "porque es cosa que en Francia no se han", 17 o la propia adopción por parte de las élites castellanas, al menos, desde las décadas de 1420-1430, de la moda a la morisca, puesta en escena en los juegos de cañas o el toreo caballeresco, como un signo de identidad grupal. ${ }^{18}$ Identidades generadas en torno a lo morisco que serán objeto de reevaluación a partir de fines del siglo XV, en el marco de la tensión entre las ideas de exotismo y de europeización, como veremos detenidamente más adelante.

En segundo lugar, el papel que pudo desempeñar la integración no solo del elemento musulmán, sino también judío, en la construcción de una imagen de la soberanía regia. Ello gracias a la participación de ambas minorías en las exequias reales o a la creación de la ficción de un receptor multiconfesional a través de inscripciones multilingües, presentes, por ejemplo, en el epitafio de Fernando III de Castilla (Fig. 1) o en las Ilaves conmemorativas de la conquista de Sevilla, ambas en la catedral de Sevilla. Unas muestras que tendrían posiblemente como objetivo explicitar el ejercicio de la soberanía regia por encima de las distintas confesiones del reino, hasta el punto de que, en casos concretos, como el citado epitafio de Fernando III, podría vincularse tal vez y de forma hipotética con concepciones universalistas del poder, ligadas a ideas de perfil imperial.

En su conjunto, estos procesos culturales se vieron favorecidos por la existencia de un conjunto de valores culturales compartidos por las sociedades de corte andalusí y casteIlana, resultado, entre otros aspectos, del intercambio de regalos diplomáticos; del contacto cotidiano de los castellanos con las diferentes manifestaciones artísticas y suntuarias andalusíes en las ciudades conquistadas al islam; o de la presencia, dentro de la Corona,

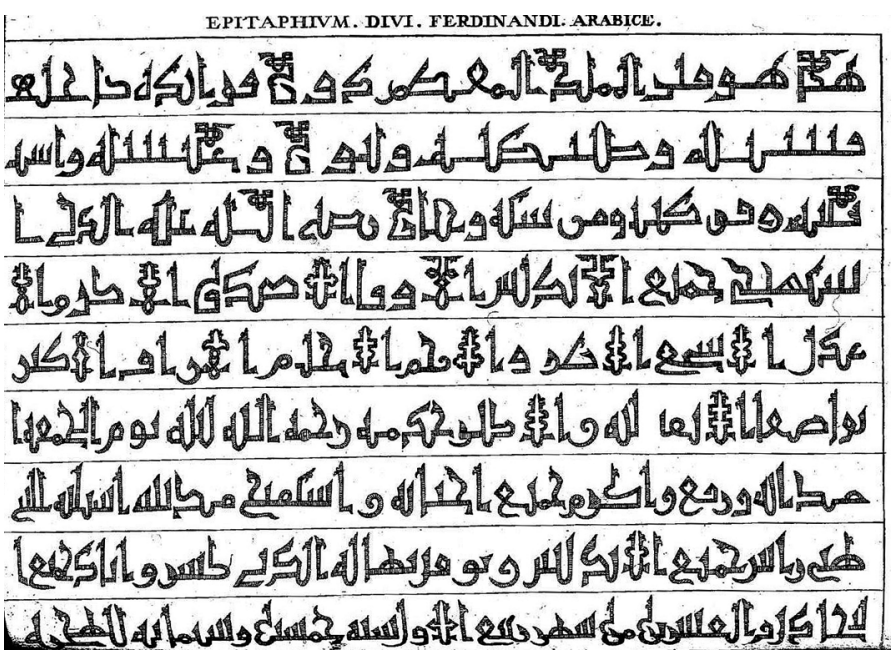

Fig. 1. Epitafio árabe de Fernando III de Castilla. Segunda mitad del siglo XIII. Catedral de Sevilla. FLÓREZ, Enrique. Elogios del santo rey Don Fernando puestos en el sepulcro de Sevilla en hebreo, y arábigo hasta hoy no publicados con las inscripciones latina y castellana. Madrid: Antonio Marín, 1754.

de zonas específicas de contacto directo con el islam.

Esta cercanía cultural, con significados asumidos de forma conjunta por una y otra parte, nos sitúa ante el debate del grado de intensidad de los procesos de traducción cultural y de recepción creativa en la asunción de la cultura andalusí por la corte real de Castilla, marcada por un horizonte cultural cristiano y condicionada por problemáticas políticas propias (configuración de identidades particulares, reforzamiento de legitimidades políticas, consolidación del Estado Moderno, etc.). ${ }^{19}$

A continuación, analizaremos los distintos ámbitos en los que se manifestará la recepción de este modelo cultural islámico.

\section{El consumo suntuario}

El interés de los reyes castellano-leoneses por la cultura material islámica parece encontrarse ligado, en sus orígenes, al gusto general de las élites occidentales alto y plenomedievales,

\footnotetext{
17 ROSELL, Cayetano (ed.), 1953, t. II, año 1411, cap. XX, p. 339.

18 NOGALES RINCÓN, David, 2019, en preparación.

19 En relación con esta cuestión, Juan Carlos Ruiz Souza señala que "hubo muy diferentes grados de asimilación y asunción del arte andalusí en la arquitectura erigida por los reinos cristianos peninsulares. En ocasiones se asimiló todo (espacio, lenguaje arquitectónico y mensaje ideológico) como se observa en ciertos palacios de la monarquía y de la nobleza del siglo XIV" (RUIZ SOUZA, Juan Carlos, 2010, p. 194).
} 
tanto religiosas como políticas, por el consumo suntuario oriental, principalmente textil, manifestado a partir de la segunda mitad del primer milenio. En este sentido, el arraigo de este consumo de lujosas telas de seda en el ámbito bizantino y el uso, en expresión de Anna Muthesius, de la diplomacia bizantina de la seda ("Byzantine silken diplomacy")20 hubo de despertar el interés por este modelo suntuario en época altomedieval, marcando así, por ejemplo, el consumo suntuario del califa fatimí, en el siglo X, o de las cortes carolingia y otónida, entre los siglos VIII y X.21 Dicho consumo suntuario, lejos de agotarse, fue alimentado por los ricos textiles islámicos, que convergerían de una forma muy clara, en el siglo $\mathrm{XI}$, con las producciones bizantinas. ${ }^{22} \mathrm{El}$ interés por estos textiles islámicos tendría continuidad a lo largo de toda la Baja Edad Media, expresado principalmente, desde fines del siglo XIII y a lo largo del siglo XIV, en el consumo de los denominados como paños tártaros y otras telas orientales. ${ }^{23}$ El testigo sería retomado, a fines del siglo XIV y durante todo durante el siglo $\mathrm{XV}$, por las producciones suntuarias italianas, así como sus imitaciones locales, inspiradas en motivos orientales, ${ }^{24}$ entre las que cabría destacar, en el contexto peninsular, el ámbito valenciano, con el despegue, a partir de las manufacturas musulmanas precedentes, de la industria de la seda desde la segunda mitad del siglo XV, centrada en diversas variedades de sedas al estilo genovés, con los terciopelos a la cabeza. ${ }^{25}$

En el contexto castellano-leonés, la presencia de estas telas está documentada, al menos, desde el siglo $X$, con motivo del envío de una túnica de seda dorada por el califa al-Hakam II (961-976) a Ordoño IV (958-960). ${ }^{26}$ Sería altamente significativo, en cualquier caso, que, en los alrededores de la ciudad de León, se documenten, ya a principios del siglo XI, unos tira- ceros del rey. ${ }^{27}$ Aunque contamos con algunos testimonios materiales aislados para los siglos XI y XII (v. gr. los tejidos islámicos de los monasterios de San Zoilo de Carrión de los Condes y de San Salvador de Oña), las mejores muestras se corresponden con el siglo XIII, con los conocidos ajuares funerarios del monasterio de Santa María la Real de Las Huelgas de Burgos; los de Fernando III (1217-1252) y Alfonso $X$ de Castilla en la catedral de Sevilla; - los del sepulcro de Sancho IV de Castilla (1284-1295) en la catedral de Toledo.

En dicho consumo pesarían, por encima de las connotaciones religiosas, unas pautas que asociaban una estética particular con la representación de la autoridad y el poder. Dicha estética, que se podría retrotraer al Bajo Imperio romano, estaría marcada por los modelos decorativos bizantinos, fuertemente influidos por los diseños de Asia central, sasánidas y sognianos, que cristalizarían entre los siglos VIII-IX. Estos modelos bizantinos serían posteriormente adoptados, a través de los contactos culturales y políticos, por los referidos textiles islámicos, depositarios de la tradición romana, sasánida, bizantina y egipcia. ${ }^{28}$ Estos modelos decorativos -compartidos por otras producciones suntuarias, como los marfiles- se basarían en la figuración, frecuentemente inserta en círculos, de animales -cuya representación incidiría ocasionalmente en la idea de dominio, a través del motivo del depredador cazandoo de escenas principescas -centradas en la caza o en la música-. Temáticas que hubieron de ser del agrado de las élites cristianas, que encontraron adicionalmente en estos tejidos, realizados en seda con hilos entorchados en oro o plata, un instrumento para la expresión de su magnificencia.

Dentro de estas pautas estéticas genéricas, cabría llamar la atención sobre tres aspectos específicos manifestados en el ámbito corte-

\footnotetext{
20 MUTHESIUS, Anna, 2004, pp. 8-9.

${ }^{21}$ MUTHESIUS, Anna, 2004, p. 137. Diversas cuestiones al respecto de estas relaciones artísticas entre la corte bizantina y la fatimí son abordadas en CUTLER, Anthony, 1999.

22 MUTHESIUS, Anna, 1997, p. 145.

23 JACOBY, David, 2010, pp. 72-81.

24 MACK, Rosamond E., 2004, p. 327; JACOBY, David, 2010, pp. 77-83.

25 NAVARRO ESPINACH, Germán, 1992, pp. 87-111, 124-125, 151-154; NAVARRO ESPINACH, Germán, 1999, pp. 101-113.

${ }^{26}$ DODDS, Jerrilynn D. et al., 2008, p. 69.

27 LARREA, Juan José, 2013, p. 47.

28 Sobre estos aspectos son de interés: JACOBY, David, 2004, MUTHESIUS, Anna, 1997, MACKIE, Louise, W., 2015, pp. 10-275, BAKER, Patricia L., 1995, pp. 35-81 y THOMAS, Thelma K., 2012, pp. 130-132.
} 
sano castellano. En primer lugar, la posible influencia andalusí en la promoción, en Castilla, del color azul como símbolo de poder, como ha sugerido María Barrigón a partir del examen del ajuar funerario de Alfonso VIII de Castilla (1158-1214). Aspecto que pudo ser, como propone verosímilmente la referida investigadora, determinante en la adopción, a través de la figura de Blanca de CastiIla, de este color en las vestiduras de los reyes franceses. ${ }^{29}$

En segundo lugar, el papel de los repertorios decorativos islámicos en la configuración de nuevos patrones estéticos vinculados a la representación visual del poder. De ello tenemos buena muestra en: a) la incorporación a los paños reales, durante el reinado de Alfonso $X$, de los repertorios decorativos basados en el uso de medallones, denominados por las fuentes como señales de rueda o paIlia rotata, propios de los repertorios sasánidas, bizantinos o islámicos. Dichos motivos sirvieron probablemente al Rey Sabio como una vía de acercamiento a la representación de la autoridad imperial, por cuanto estos se encontraban ligados, posiblemente bajo la influencia de los propios repertorios decorativos orientales, a la figura del emperador romano-germánico; ${ }^{30}$ b) la adopción de pautas decorativas islámicas como modelo de las novedosas decoraciones emblemáticas casteIlanas basadas en sembrados heráldicos, ${ }^{31}$ que bien pudieron ser el origen de la difusión de este patrón por el resto del espacio europeo; ${ }^{32}$ c) la aparición, durante el reinado de Fernando III de Castilla, del cuartelado para la combinación de las armerías reales, cuya génesis probablemente no se podría entender sin tener en cuenta las composiciones en damero características de las telas orientales y sus imitaciones cristianas; ${ }^{33}$ d) la influencia de los repertorios decorativos textiles sobre las decoraciones arquitectónicas, como mostrarían, por ejemplo, las yeserías del claustro de San Fernando del monasterio de Las Huelgas de Burgos.

En tercer lugar, en la preferencia que tuvo la corte castellana, bajo la posible influencia andalusí, hacia perlas y piedras preciosas, que cabría relacionar no solo con cuestiones estéticas, sino también mágicas. Tal vez la mejor muestra de este interés se encuentre en las estrategias de Pedro I de Castilla (1350-1369) para configurar, inspirado probablemente por el sultán de Granada, un gran tesoro real, en el que se integrarían algunas de las "joyas ricas de aljófar e piedras preciosas" confiscadas en 1362 al Rey Bermejo de Granada. ${ }^{34}$

\section{El ritual cortesano}

El ascendiente andalusí sobre el ritual cortesano castellano se manifestó particularmente en el marco escenográfico en el que tendría lugar la presentación ceremonial del soberano: un estrado revestido y enmarcado por alhamares y alfombras, cuyo uso aparece bien definido ya en la Estoria de España alfonsí. ${ }^{35} \mathrm{El}$ revestimiento con alfombras no quedó restringido al ámbito palatino, sino que, como tenemos constancia, al menos, desde el siglo XIV, debieron de tener amplia presencia en los panteones regios. ${ }^{36}$ Este uso se comple-

\footnotetext{
29 BARRIGÓN, María, 2015, pp. 166-169.

30 Estos repertorios marcarían la disposición en círculos de la decoración emblemática de la conocida como Dalmática de las águilas (Kunsthistorisches Museum, Viena), que habría que entender como una adaptación a la manera gótica de estos esquemas orientales, en línea con diversas capas pluviales, realizadas en el ámbito inglés en el conocido como opus anglicanum, sobre las que es de interés BROWNE, Clare et al. (ed.), 2017, nos. cat. 22, 23, 31, 33, 37, 38, 45, 46, 49, 52. En la transmisión de estos motivos en el contexto de la corte imperial hubieron de tener un papel fundamental piezas como el Chormantel de santa Cunegunda (Museo Diocesano, Bamberg), considerado tradicionalmente como un textil de origen germano y al que actualmente se le asigna un origen bizantino (WOODFIN, Warren T., 2008, pp. 33-50).

31 Dicha relación ha sido apuntada igualmente en BÖSE, Kristin, 2016, pp. 221-222 y MENÉNDEZ PIDAL, Faustino, 2011 , p. 126.

32 Plantea la misma duda TOLLEY, Thomas, 1991, pp. 182-184, con la presentación de algunos ejemplos sobre los paralelos compositivos entre repertorios hispánicos y franceses o ingleses en MENÉNDEZ PIDAL, Faustino, 1994, pp. 38-40.

33 Cf. MENÉNDEZ PIDAL, Faustino, 2011, pp. 121-122.

34 Sobre el tesoro de Pedro I, véase GRASOTTI, Hilda, 1988.

35 PÉREZ HIGUERA, Teresa, 1987, pp. 25-26. Aunque contamos con una referencia temprana sobre el conde Sancho de CastiIla, relativa a 1016-1017, citada en PÉREZ HIGUERA, Teresa, 1996, p. 144, esta es un tanto ambigua. De este uso dan buena cuenta las referencias a alfombras conocidas para las cortes de Enrique III, Juan II o Isabel I de Castilla, en CAÑAS GÁLVEZ, Francisco de Paula, 2010, p. 113 y GONZÁLEZ MARRERO, Maa del Cristo, 2004, pp. 143-144.

36 NOGALES RINCÓN, David, 2010, p. 782.
} 
mentó, sobre todo en verano, con los guadamecíes, empleados en el revestimiento de suelos y estrados. ${ }^{37}$ Especialmente en los espacios más íntimos de palacio y en aquellos contextos más informales, parece que sería posible encontrar, siguiendo la tradición andalusí, a los reyes castellanos sentados a la turca, en almohadas, directamente sobre el estrado alfombrado, tal como se representa en distintas figuraciones del Libro de los juegos de Alfonso $X$ y como sugieren algunas noticias puntuales relativas a Enrique IV (1454-1474) o a la corte de Isabel I (1474-1504). ${ }^{38}$

Este uso no fue impedimento para que, en aquellos contextos ceremoniales y públicos, la imagen ritual e iconográfica del poder regio quedara asociada al trono, siguiendo pautas comunes a la cristiandad medieval, donde la posición sedente se encontraba estrechamente asociada con la autoridad y el poder. En este supuesto, quizá como influencia de los modelos de tronos andalusíes, el rey castellano se presentaría frecuentemente sobre un trono bajo, ${ }^{39}$ al modo en que muestran diversos testimonios iconográficos, como la miniatura alfonsí, los testimonios del Archivo de la Catedral de Sevilla, sección IX, carpeta 116, $\mathrm{n}^{\circ} 42$ y de la Biblioteca Nacional de España (BNE), Manuscritos, Mss. 12794, fol. 2r., o las piezas numismáticas conocidas como enriques de la silla baja. A los pies del rey entronizado, se encontrarían, al menos, en algunos contextos ceremoniales, los miembros de la corte sentados directamente en el suelo sobre almohadas, según el uso andalusí, como sugieren las figuraciones del tratado Notule de primatu nobilitate et dominio ecclesiae Toletanae (ca. 1240), ${ }^{40}$ la mi- niatura alfonsí, los testimonios sobre las recepciones, en Valladolid, por parte de Juan II de Castilla, de una embajada enviada por el rey de Granada (1409) ${ }^{41}$ y, en Medina del Campo, por parte de los Reyes Católicos, de una embajada inglesa (1489) ${ }^{42}$ o el ritual de juramento de la infanta Isabel y de su marido Manuel I de Portugal en la catedral de Toledo (1498). ${ }^{43}$ Además del estatus, el género hubo de ser un condicionante fundamental en la adopción de este uso, como sugieren Antonio de Lalaing, con ocasión del primer viaje de Felipe el Hermoso a la Península en 1501, y diversas noticias tardías que lo presentarían, a lo largo de los siglos XVI y XVII, como una costumbre propia del género femenino, ${ }^{44}$ probablemente por la estrecha vinculación de las mujeres con lo doméstico.

Junto a estas prácticas genéricas de la exhibición regia, cabría destacar la posible adopción, a lo largo del reinado de Pedro I de Castilla, de la práctica de la exhibición del monarca ligada a la tipología de la "fachada-trono". En este sentido, desde la fachada de su palacio en los Reales Alcázares de Sevilla, como sugiere Ruiz Souza, el monarca, siguiendo un uso ritual que podría remontarse a la Antigüedad, se mostraría en majestad ante el espacio de la plaza de la Montería. ${ }^{45}$

Más allá del ceremonial de exhibición regia, las influencias andalusíes en la definición de los modelos rituales y simbólicos de la corte castellana son diversas. Entre estas cabría citar, en primer lugar, la importancia alcanzada por la cetrería entre las élites políticas castellanas bajomedievales, tal vez gracias, entre otros factores, al influjo andalusí. ${ }^{46} \mathrm{En}$

\footnotetext{
37 TORRES BALBÁS, Leopoldo, 1951, p. 94; PÉREZ HIGUERA, Teresa, 1987, pp. 27-28; SILVA SANTA-CRUZ, Noelia, 2004, p. 151. Dos ejemplos para las cortes de Enrique III e Isabel I respectivamente en: NOGALES RINCÓN, David, 2014, p. 107 y GONZÁLEZ MARRERO, Ma del Cristo, 2004, pp. 149-150.

38 PÉREZ HIGUERA, Teresa, 1996, p. 144; SILVA SANTA-CRUZ, Noelia, 2004, p. 142.

39 Sobre estos tronos bajos, véase PÉREZ HIGUERA, Teresa, 1994, pp. 36-48.

40 BNE, Manuscritos, Vit. 15-5, ff. 3r-12v.

${ }^{41}$ GARCÍA DE SANTA MARÍA, Alvar, 1982, cap. 122, p. 268.

42 BELLO LEÓN, Juan Manuel; HERNÁNDEZ PÉREZ, Ma Beatriz, 2003, p. 193.

43 RESENDE, Garcia de, 1973, pp. 306-307.

${ }^{44}$ Sobre esta cuestión, véase MARTínEZ NESPRAL, Fernando, 2007, pp. 105-111.

45 RUIZ SOUZA, Juan Carlos, 2004, p. 27; RUIZ SOUZA, Juan Carlos, 2013, pp. 316-317; RODRÍGUEZ MORENO, Concepción, 2015, pp. 360, 468. Este modelo pudo repetirse igualmente en el alcázar de Segovia, imitado, a su vez, en los castillos de Coca, Belmonte, el de la Mota de Medina del Campo y Manzanares el Real y, por influencia de la reina Leonor de Castilla, mujer de Carlos III, en el palacio de Olite, como sugiere RUIZ SOUZA, Juan Carlos, 2013, pp. 317-320 y RUIZ SOUZA, Juan Carlos, 2014, pp. 40-43

${ }^{46}$ NOGALES RINCÓN, David, 2017, pp. 262-263; SILVA SANTA-CRUZ, Noelia, 2005, pp. 270-271.
} 
segundo lugar, la difusión de la monta a la gineta, vinculada, en el plano del ritual cortesano, a las fiestas de toros y juegos de cañas. ${ }^{47}$ En tercer lugar, la especial inclinación por el empleo de sustancias aromáticas en la corte regia. ${ }^{48}$ En cuarto y último lugar, la contribución -no restringida al área peninsular, donde quizá se podría documentar de forma más temprana- a la promoción política del león, así como de otros animales (elefante, águila, pavo). Ello gracias a la influencia de los repertorios decorativos propios de la tradición bizantina e islámica y de ciertos recursos retóricos, como el uso, en el ámbito islámico, de la imagen del león como instrumento para poner de relieve el poder y la fortaleza del soberano. ${ }^{49}$

\section{La arquitectura palatina}

La arquitectura palatina ha sido un campo preferente de atención por parte de aquellos estudios artísticos que han abordado la recepción del modelo andalusí en la corte castellana. Un momento fundamental de este proceso de recepción parece encontrarse en la conquista de Toledo (1085), que pondría en contacto directo a los conquistadores cristianos con la arquitectura andalusí. ${ }^{50}$ Dicho proceso de asimilación debió de ser paulatino. Las primeras iniciativas que manifestarían un interés claro por los modelos andalusíes se documentan, al menos, desde el reinado de Alfonso VIII de Castilla, con el proyecto del Palacio Mayor del alcázar de Segovia ${ }^{51}$ o las problemáticas intervenciones en la capilla de la Asunción del monasterio de Santa María la Real de Las Huelgas de Burgos o en la de San Ildefonso del alcázar de Guadalajara. ${ }^{52}$ En dichas empresas, se adoptarían formas y, en ocasiones, estéticas propias de lo andalusí, pudiéndose acaso pensar, siguiendo a Ja- vier Martínez de Aguirre, en la progresiva asociación que se produciría entre ciertas funcionalidades y determinadas formulaciones espaciales y estéticas andalusíes. ${ }^{53}$

Entre estas empresas de Alfonso VIII y las de Alfonso XI de Castilla (1312-1350), es decir, a lo largo del siglo XIII y las primeras décadas del siglo XIV, la incorporación de pautas andalusíes debió de tener continuidad, aunque de una forma lenta, especialmente debido al impulso dado al arte gótico por Alfonso $X$, que no sería ajeno a su programa político de aspiración al trono imperial. Un período en el que debió de ser fundamental el contacto con las nuevas realidades andalusíes, fruto de la anexión a la Corona de Castilla de Murcia (1243) y del valle del Guadalquivir, con Córdoba (1236) y Sevilla (1248) a la cabeza.

Parece que esta incorporación de pautas islámicas hubo consolidarse en el reinado de Alfonso $\mathrm{XI}$, especialmente a lo largo del segundo cuarto del siglo XIV, coincidiendo con su mayoría de edad y el reforzamiento del poder real -con las iniciativas en el Real Alcázar de Córdoba, las probables en el palacio de Tordesillas y en la sala de la Justicia de los Reales Alcázares de Sevilla (Fig. 2), y las más hipotéticas en el alcázar de Guadalajara-, en el marco del proceso que Ruiz Souza ha denominado como de "reinteriorización" de la Corona de CastiIla. ${ }^{54}$ Intervenciones a las que quizá no fue ajeno el contacto directo de Alfonso XI con estas formas andalusíes, fruto de sus frecuentes visitas a Andalucía en el marco del desarrollo de la cruzada. Todo este proceso dejaría rastro en la referencia del Libro del caballero Zifar a esa "alcoba muy alta a bóveda, e la bóveda era toda labrada de obra morisca de unas piedras çafires muy finos",55 buena muestra del afianzamiento al que estaban asistiendo, en el imaginario cortesano caste-

\footnotetext{
47 Sobre esta cuestión, véase FALLOWS, Noel, 2010, pp. 267-303; NOGALES RINCÓN, David, 2019, en preparación.

48 SILVA SANTA-CRUZ, Noelia, 2005, pp. 271-272.

49 SILVA SANTA-CRUZ, Noelia, 2014, pp. 13-15; NOGALES RINCÓN, David, 2017, pp. 262-263, 266-267; MARTíNEZ DE LAGOS FERNÁNDEZ, Eukene, 1997, pp. 320-323, 328.

50 BORRÁS GUALIS, Gonzalo, 1990, p. 81.

51 ALMAGRO GORBEA, Antonio, 2008, pp. 59, 61. En su estado actual, cabría quizá separar del proyecto original de Alfonso VIII los zócalos decorados, que han sido datados de forma hipotética por Carmen Rallo Gruss durante el reinado de Alfonso X, emulando tipologías almorávides presentes en Murcia (RALLO GRUSS, Carmen, 2003, pp. 396-397).

52 PRADILLO Y ESTEBAN, Pedro José, 2003, pp. 15-16.

53 MARTíNEZ DE AGUIRRE, Javier, 2017, pp. 489-493.

${ }^{54}$ RUIZ SOUZA, Juan Carlos, 2012, p. 136.

${ }_{55}$ Libro del caballero Zifar, ed. J. González Muela, 1990, p. 427 cit. en RUIZ SOUZA, Juan Carlos, 2007, p. 232.
} 


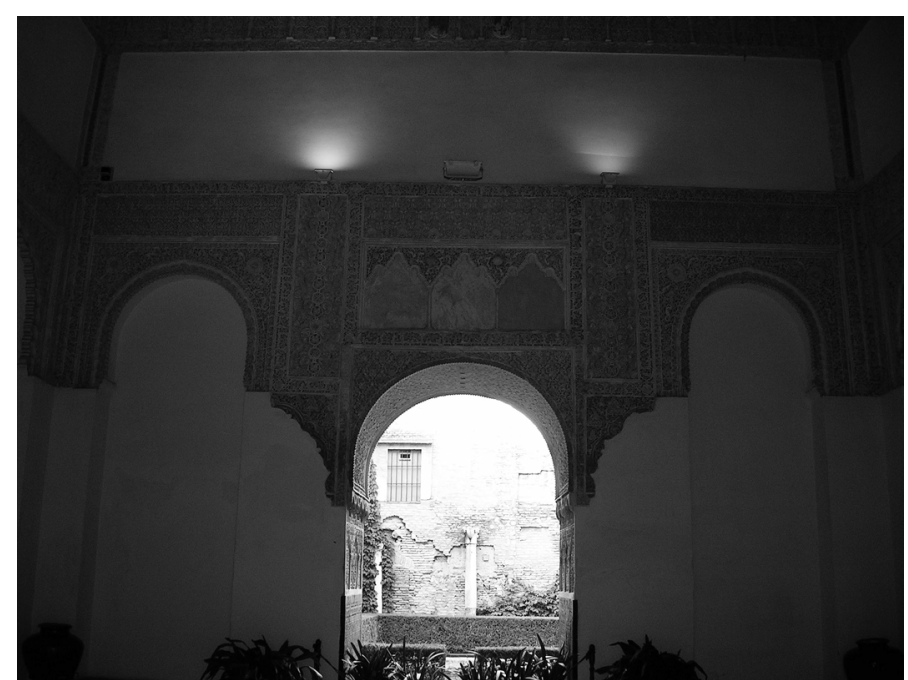

Fig. 2. Sala de la Justicia. Reales Alcázares de Sevilla. Mediados del siglo XIV. Fotografía: Autor.

llano, estas formas a lo largo de las primeras décadas del siglo XIV, si atendemos a la cronología sugerida por José Manuel Cacho Blecua para esta obra de ca. 1321-1350. ${ }^{56}$

Estos proyectos artísticos de Alfonso XI, unidos a otras iniciativas que tienen lugar en el ámbito toledano o hispalense al margen de la corte, como resultado de la iniciativa nobiliaria, ${ }^{57}$ permiten entender con mayor facilidad la configuración de lo que Pérez Higuera ha denominado como el "modelo del palacio mudéjar", surgido a mediados del siglo XIV, fruto de las empresas artísticas de Pedro.$^{58}$ A través de dichas empresas, este rey hubo de impulsar una arquitectura emblemática, que, tras algunos ensayos previos en AstudiIlo (Palencia) (Fig. 3) o Tordesillas (Valladolid), culminaría en la construcción de su palacio sevillano, buscando mostrar la supremacía del poder regio. ${ }^{59}$
En las décadas que siguieron a la caída del rey don Pedro, esta arquitectura emblemática estaría llamada a tener gran éxito como símbolo de poder de la realeza y la nobleza castellana. Así, este horizonte artístico impulsado por Pedro I es el que encontraría Enrique II de Castilla (1369-1379) a su llegada al trono. Pronto fue incorporado, en el marco de la construcción de la imagen regia, a las iniciativas artísticas de la nueva dinastía, tal como se manifestaría en las intervenciones de su fundador en el palacio real de León o en la capilla real y la puerta del Perdón de la catedral de Córdoba. Intervenciones prolongadas en aquellas actuaciones en los alcázares de Madrid, Murcia, Segovia o Valladolid, en el pabellón de caza de Miraflores en Burgos o en la capilla de Reyes Nuevos de la catedral de Toledo, desarrolladas a fines del siglo XIV e inicios del siglo XV, principalmente bajo el impulso de Enrique III (1390-1406). Dichas intervenciones no parecen ser casuales, sino que se centrarían en aquellos espacios de especial relevancia simbólica para la realeza, como el panteón dinástico de Reyes Nuevos o los alcázares de Madrid y Segovia, ubicados en el nuevo eje de poder que se estaba gestando en la Corona. Se trataría, por ello, de proyectos susceptibles de ser puestos al servicio directo de las estrategias de representación de una monarquía en expansión, dentro del proceso de génesis del Estado Moderno. A estas iniciativas se hubo de sumar pronto la nobleza que, en el entorno regio, mostraría un interés por este modelo mudéjar a partir de la década de $1370 .{ }^{60}$

Así el impulso a estas iniciativas artísticas que tienen como marco la tradición andalusí se podría explicar, dentro del contexto general de consolidación de la virtud aristotélica de la magnificencia, por un lado, atendiendo sobre todo a condicionantes internos, con una dinastía Trastámara que buscaría en este modelo un instrumento de representación del po-

\footnotetext{
56 CACHO BLECUA, José Manuel, 1995, p. 62.

57 Pensamos en iniciativas tanto a nivel compositivo, como la portada del palacio toledano de los Oter de Lobos (PASSINI, Jean, 2007), como organizativo, como los palacios toledanos de don Juan Manuel, casa de María Meléndez o el corral de don Diego, o el sevillano de doña María Alfonso Coronel (RODRÍGUEZ MORENO, Concepción, 2015, pp. 248, 297-298, 511 y MARTíNEZ CAVIRÓ, Balbina, 1980).

58 PÉREZ HIGUERA, Teresa, 1987, p. 15.

59 RODRÍGUEZ MORENO, Concepción, 2015, p. 232

60 PÉREZ HIGUERA, Teresa, 1993, p. 109; PÉREZ HIGUERA, Teresa, 1996, p. 131. Un análisis de interés en torno al caso particular de los Velasco en PAULINO MONTERO, Elena, 2016.
} 
der regio, y una nobleza, estrechamente vinculada con la nueva dinastía, que encontraría en dicho modelo un signo de identidad. Por otro lado, atendiendo a condicionantes externos, relacionados con el deseo de ofrecer una imagen adecuada de la monarquía para su representación internacional, acaso condicionada por influencias foráneas que parecen adivinarse en los años finales del siglo XIV. ${ }^{61}$

Al margen de motivaciones materiales y prácticas (artífices, materiales, costes, tradición constructiva), cuyo peso no siempre es fácil de establecer con precisión, tres parecen ser las causas que explicarían el interés por este modelo artístico andalusí a lo largo del período bajomedieval. En primer lugar, el aspecto visual, gracias a la incorporación de ricas armaduras de madera, de yeserías o de azulejería, complementadas por el uso de alfombras. En segundo lugar, el simbolismo de algunas fórmulas arquitectónicas, particularmente el carácter centralizado de la qubba, cuya dimensión cósmica sería puesta de relieve por el Libro de la miseria del omne (primera mitad del siglo XIV), al describir la torre hecha por el rey Cosroes. ${ }^{62}$ En tercer lugar, los aspectos funcionales, pudiéndose quizá pensar: a) en el interés que el modelo andalusí de sala oblonga con las alcobas o alhanías en los extremos revestiría, a nivel práctico, para el desarrollo de ciertos rituales regios, por su capacidad para definir una jerarquización simbólica y funcional entre el espacio central y los espacios contiguos; b) en la practicidad de los pasadizos sobreelevados, probable derivación de los conocidos como sâbâtâ andalusíes, presentes, por ejemplo, en Córdoba o en Sevilla, empleados para conectar espacios religiosos y residenciales; conexión de la que además se podrían derivar algunas imágenes simbólicas acerca del estrecho vínculo entre poder político y religioso. ${ }^{63}$

Con un sentido más global, la configuración, en la Corona de Castilla, de diversas villas y ciudades -como Toledo, Burgos o Segovia, y,

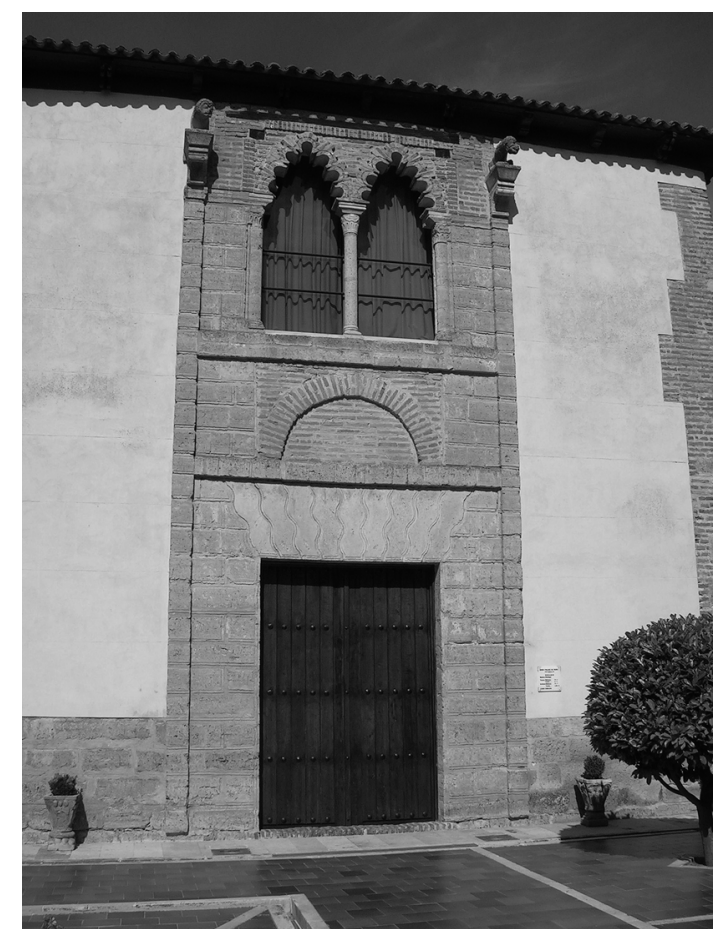

Fig. 3. Fachada del palacio de Pedro I de Astudillo (Palencia). Ca. 1354-1369. Fotografía: Autor.

de una forma simplificada, Medina del Campo o Arévalo- en las que se definirían diversos centros de poder en torno a una especialización funcional (alcázar, palacio urbano, casa de campo) ha sido presentada por Pérez Higuera como una posible herencia andalusí. ${ }^{64}$ Aunque queda fuera de toda duda la importancia de dicha herencia en la génesis de la tipología del alcázar en Castilla y el modelo en sí mismo parece viable para momentos tempranos, podría, sin embargo, plantear más dudas para etapas más tardías, como las intervenciones de Enrique III en Burgos (pabellón de caza de Miraflores) o Enrique IV en Segovia (palacio de san Martín, pabellón de caza del Campillo). ${ }^{65}$

61 Cf. PAULINO MONTERO, Elena, 2017, pp. 153-156; NOGALES RINCÓN, David, 2014, pp. 129-130.

${ }^{62}$ CUESTA SERRANO, Jaime (ed.), 2012, p. 127, c. 181.

${ }^{63}$ NOGALES RINCÓN, David, 2010, pp. 346, 646-647; CÓMEZ RAMOS, Rafael, 1988, pp. 14-19.

64 PÉREZ HIGUERA, Teresa, 1993, pp. 80-83.

65 Los palacios urbanos tardíos pudieron responder a la simple emulación, por motivos prácticos, del modelo de las casas urbanas de la nobleza, donde los reyes acostumbraban alojarse en su itinerancia por la Corona. En lo que respecta a las casas de campo o pabellones de caza, aunque su presencia no sería un hecho inédito en el período anterior a Enrique III, estos parecen adquirir un especial impulso a fines del siglo XIV, paralelo al interés por definir una red palacial. Estas seguirían tal vez modelos foráneos, antes que la tipología de la almunia andalusí -bajo el modelo que la historiografía define como hunting lodge, château de la chasse, relais de la chasse, château forestier, pavillon de chasse o casina di caccia, ampliamente difundido a fines del siglo XIV en Francia, en Inglaterra o en Italia-, aunque pudieran adoptar formulaciones estéticas que remitían a lo andalusí. 


\section{El modelo tardogótico y la redefinición del modelo andalusí a fines de la Edad Media}

Lo que había sido la integración de diversos elementos propios del modelo cultural islámico en la definición de una imagen de la monarquía asistió a una redefinición a partir de las décadas iniciales del siglo XV. Dicha redefinición fue consecuencia del progresivo influjo de un nuevo modelo cultural, conocido como tardogótico o borgoñón, que, irradiado desde el ámbito septentrional de Europa, adquirió la condición de base conceptual y estética de la cultura tardomedieval de corte, con pretensiones de articular, en el ámbito artístico, un lenguaje internacional cortesano para el ámbito de la cristiandad. Un modelo que se manifestaría con claridad durante el reinado de Juan II y que asistiría a un especial impulso en las décadas finales de la Edad Media, vinculado a la reorientación cristiana de la monarquía durante el reinado de los Reyes Católicos. Esta reorientación se presentaría, por un lado, como reacción frente a las imágenes filoislámicas proyectadas sobre Enrique IV por la propaganda de su hermano el príncipe don Alfonso, elevado al trono castellano como Alfonso XII de Castilla (1465-1468), y de la propia Isabel l; y, por otro lado, como un instrumento para asentar las pretensiones de la monarquía hispánica de convertirse en cabeza de la cristiandad, materializadas en esos procesos de "desemitización" y de "europeización" a los que se ha referido Alain Milhou. ${ }^{66}$

Dichos cambios se manifestaron en la penetración en la corte de Castilla de las renovadas tendencias artísticas tardogóticas. La expansión de estas nuevas influencias foráneas a partir de las décadas de $1430-1440$ no supuso un desplazamiento del antiguo interés por la estética andalusí, aunque sí favoreció una revitalización de los repertorios góticos (motivos vegetales, figurativos, geométricos) en la decoración de espacios particulares, como los arrocabes y las albanegas. Buena muestra de estas iniciativas en el ámbito regio cabe encontrarlas en la capilla mayor de la iglesia monástica de Santa Clara la Real de Tordesillas, realizada a mediados del siglo $X V$, y en las intervenciones enriqueñas tanto en el alcázar de Segovia, efectuadas a partir de 1451, como en San Antonio el Real de Segovia (Fig. 4), ejecutadas durante el tercer cuarto del siglo XV.

Estas tendencias tardogóticas adquirieron un predominio destacado, durante el último cuarto del siglo XV e inicios del siglo XVI, en los proyectos religiosos desarrollados por Isabel I. En estos proyectos, como señaló Rafael Domínguez Casas, la reina habría buscado "manifestar estéticamente su programa de unidad religiosa a través del estilo hispanoflamenco, al que ella misma consideraría como quintaesencia de lo europeo y cristiano" ${ }^{67}$ Este claro interés de la Reina Católica por las formas tardogóticas no supuso, en modo alguno, una renuncia completa a la herencia previa. El horizonte andalusí no hubo de ser, como se pretendió en el pasado, con la definición del estilo Isabel como resultado de la hibridación de las formas mudéjares y tardogóticas, una invariable en las iniciativas de artífices como Juan Guas. ${ }^{68}$ Sin embargo, es posible pensar que la apreciación y percepción de la estética tardogótica en Castilla pudo estar guiada o mediatizada por ese gusto previo de raíz andalusí hacia "la exuberancia y profusión ornamental y las complicaciones decorativas" .69 También, la herencia andalusí moldearía, dentro de las empresas artísticas religiosas de Isabel I, el gusto por las inscripciones que recorrerían los muros de los templos y otros elementos asociados a la tradición plurisecular artística castellana, como la presencia de armaduras de madera y de yeserías, o la concepción de la cabecera como un espacio autónomo centralizado.

Esta continuidad con la tradición andalusí se evidenciaría particularmente, durante el reinado de Isabel I, en las reformas de los alcázares mudéjares y andalusíes, que buscarían la unidad estilística con los edificios preexistentes, como muestran las iniciativas artísticas desarrolladas en Córdoba, Sevilla, Zaragoza o Granada. ${ }^{70} \mathrm{El}$ interés por vincularse y

\footnotetext{
${ }^{66}$ MILHOU, Alain, 1993.

67 DOMÍNGUEZ CASAS, Rafael, 2004, p. 81.

${ }^{68}$ Un examen sobre esta cuestión, en torno a la figura de Guas, en GONZÁLEZ RAMOS, Roberto, 2011.

69 TORRES BALBÁS, Leopoldo, 1949, p. 347.

70 Sobre estas reformas, véase CASTILLO OREJA, Miguel Ángel, 2001.
} 
conservar este legado palatino andalusí, en el marco de un contexto de exaltación religiosa, no solo sería una expresión del interés artístico por estas arquitecturas y de la continuidad de una tradición visual asociada con la representación del poder regio. También hubo de constituir, como ha apuntado Miguel Ángel Castillo Oreja, un "exponente de la victoria cristiana sobre el Islam". ${ }^{71}$

Igualmente, el influjo de este modelo borgoñón se manifestó en una nueva estética de la indumentaria regia, que tendió a sustituir, a partir de la segunda mitad del reinado de Juan II, las sedas moriscas listadas y las coloridas decoraciones emblemáticas por terciopelos de colores oscuros (negro; morado, azul o carmesí oscuros). No obstante, dicho cambio, aunque profundo, no hubo de suponer una ruptura radical con respecto a las concepciones estéticas previas, si tenemos en cuenta, por un lado, la continuidad en el gusto por los colores densos, la importancia de la seda como materia prima o la adopción de esquemas decorativos orientales, ahora presentados a través de la mirada de las industrias textiles italianas, ${ }^{72}$ por otro lado, si atendemos al interés de las élites políticas de la Corona por poner en escena, en los juegos de cañas y el toreo caballeresco, los coloridos arreos de la gineta y los vestidos a la morisca, utilizados como una suerte de traje de gala o festivo, a través del cual se perpetuaría esta antigua concepción estética del poder. ${ }^{73}$

Por último, dicho cambio se manifestó en el probable impulso dado al gusto por lo exótico, fenómeno asociado a los hábitos de consumo de las élites políticas de la cristiandad tras la Crisis del siglo XIV. Las percepciones del mundo andalusí por parte de los castellanos parece que estaban lejos de la idea de exotismo. Sin embargo, el gusto del modelo tardogótico por esta idea, junto con otros condicionantes, como el posible peso entre los castellanos de las percepciones de los viajeros extranjeros, pudo alimentar, desde una mirada distanciada hacia lo andalusí, el interés por explotar esta noción por parte de las élites políticas castellanas. Este gusto por lo

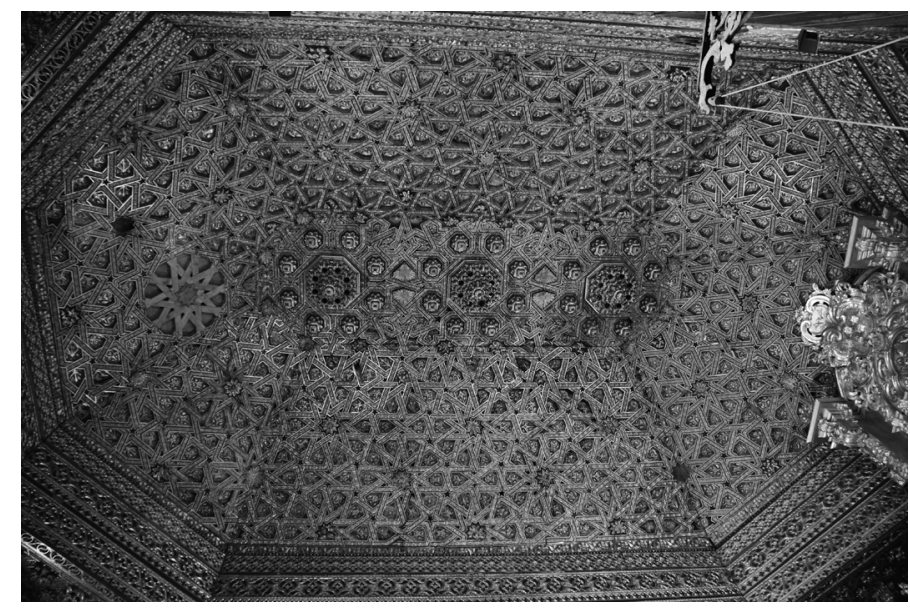

Fig. 4. Capilla mayor de la iglesia del convento de San Antonio el Real de Segovia. Tercer cuarto del siglo XV. Fotografía: Diana Lucía Gómez-Chacón.

exótico ayudaría a entender mejor -aunque no lo explica por completo, pues se podrían aducir, según los casos, otros condicionantesla destacada presencia, dentro de la cultura de corte castellana de las décadas finales de la Edad Media, de expresiones como los músicos y las danzas moriscas; la fundación de la guardia morisca, vigente durante los reinados de Juan II y Enrique IV; la introducción del juego de cañas como ejercicio caballeresco cortesano; o la difusión de la referida moda a la morisca en la corte de Castilla y entre las élites políticas de la Corona a lo largo de la primera mitad del siglo XV.

El interés que la realeza castellana mostraría por el modelo internacional tardogótico, acompañado de la referida europeización, acabó desembocando, en el campo de las identidades, en una depuración de la herencia islámica, que había marcado el devenir de la cultura cortesana, en particular, y de la castellana, en general, durante la Baja Edad Media. El complejo panorama sociopolítico tardomedieval habría de generar así, en la conformación de las identidades, una tensión interna entre lo percibido como ajeno y

71 CASTILLO OREJA, Miguel Ángel, 2001, p. 127. En esta dirección, es significativa la carta, dada por Juana I de Castilla en 1515 en la que expresaría su deseo de que la Alhambra "esté muy bien reparada e se sostenga, porque quede para siempre perpetua memoria" de la conquista de la ciudad de Granada y del citado palacio (cit. en LÓPEZ GUZMÁN, Rafael, 2001, p. 148).

72 Sobre este aspecto, véase NOGALES RINCÓN, David, 2016, pp. 238-244.

73 NOGALES RINCÓN, David, 2019, en preparación. 
lo percibido como propio, que se confrontaba, a su vez, con las percepciones externas que procedían del norte de Europa. Esta tensión tuvo al mudejarismo como parte central de un debate que, iniciado a fines del período medieval, habría de tener continuidad a lo largo de la Edad Moderna. ${ }^{74}$ Mientras algunos elementos concretos de este modelo fueron desechados, otros se integraron en la construcción de los modos o maneras nacionales, que emergerán con fuerza en este momento, al ser considerados, frente al influjo francés o italiano, como expresiones culturales propias de Castilla. ${ }^{75}$

\section{Conclusión}

El fenómeno conocido como mudejarismo, que agrupa una diversidad de manifestaciones, constituye un aspecto de interés para entender la representación del poder regio en Castilla. El proceso de recepción del modelo cultural islámico no fue uniforme ni en sus ritmos ni en sus campos de interés ni en sus motivaciones. Por el contrario, se encontró sujeto a una multiplicidad de condicionantes (prácticos, culturales, políticos, etc.), que orientaron y mediatizaron la aproximación a lo andalusí.

Al estudiar la recepción del modelo cultural islámico en la corte de Castilla, es posible observar un conjunto de inquietudes comunes a la representación del poder en el espacio mediterráneo sobre las que se sentarían las bases de este mudejarismo cortesano. Dicho gusto, que podría ser retrotraído a la Tardo- antigüedad, adoptaría perfiles bien definidos en torno a la creación de un lenguaje visual del poder con una dimensión global, que superaría lo étnico o lo religioso, ${ }^{76}$ difundido, en buena medida, gracias a los repertorios decorativos impulsados desde el ámbito bizantino y reformulados bajo el paradigma islámico. Paradigma que afianzó este imaginario visual del poder, a la vez que potenció el componente lingüístico, asociado al uso de inscripciones en caracteres cúficos o pseudo-cúficos, que acabarían por decorar no solo los textiles, sino también la arquitectura y otros objetos. ${ }^{77}$

Este gusto global se manifestaría tempranamente en el interés creciente por las telas orientales, que, a partir de los siglos VIIII-IX, inundarían Occidente, no solo para la confección de las vestiduras principescas, sino también para la envoltura de reliquias o la realización de vestiduras eclesiásticas, en tanto que, en palabras de Muthesius, dichas telas "served to underline the expression of authority in both the Imperial and in the ecclesiasticals realms" ${ }^{78}$ Dicho gusto se diversificaría a lo largo del período pleno y bajomedieval. En este sentido, el contexto italiano es una buena muestra del interés por lo islámico, motivado por su posición central dentro del Mediterráneo y su situación privilegiada en las rutas de intercambio. Interés que se concretó en la presencia de cerámica desde el siglo XI, en la representación pictórica de alfombras $u$ otros objetos islámicos a partir, al menos, del siglo XIII, en la importación de azulejos ibéricos desde mediados del

${ }^{74} \mathrm{El}$ estudio de algunas de estas cuestiones durante el período moderno, como el papel del modelo cultural islámico en la definición de la identidad española y la relectura llevada a cabo por diversos historiadores en los siglos XVI y XVII acerca del patrimonio artístico y cultural de origen andalusí, interpretado como troyano, romano o fenicio, ha sido abordado recientemente en FUCHS, Barbara, 2011, URQUÍZAR HERRERA, Antonio, 2017 o IRIGOYEN GARCÍA, Javier, 2014.

75 Así, frente a los estilos a la romana y a la moderna, considerados como foráneos, la condesa de Feria, al hablar, en 1480, de la capilla mudéjar del hospital de San Miguel de Zafra por ella fundado, se refiere a la misma como "obra de esta tierra" (MOGOLLÓN CANO-CORTÉS, Pilar, 2010, p. 270). En dicha manera o modo castellano se integrarán diversos elementos de origen islámico, en los ámbitos ritual ( $v$. gr. los juegos de cañas), artístico ( $v$. gr. la azulejería o las armaduras en madera, definidas como "artesonado dorado estilo español" por MÜNZER, Jerónimo, 2002, p. 213) o suntuario (v. gr. el estrado y las alfombras en el entorno doméstico, y las joyas ornamentadas con balajes, perlas y otras piedras preciosas, cuya estética sería denominada en la corte inglesa de principios del quinientos bajo la etiqueta de "Spanish work"). Diversas referencias al respecto aparecen compiladas en MARTíNEZ NESPRAL, Fernando, 2007, FUCHS, Barbara, 2011 y CAHILL MARRÓN, Emma Luisa, 2014, pp. 48-50.

${ }^{76}$ FELICIANO, Ma Judith, 2003, pp. 105-106, 109; MACKIE, Louise, W., 2015, p. 183; ALEMANY, Joan; BARRAL I ALTET, Xavier; GARCÍA BIOSCA, Joan E., 2004, p. 18; RUIZ SOUZA, Juan Carlos 2007, p. 207.

77 El interés por la escritura probablemente se encontrara, entre otros aspectos, en el deseo por dar un aspecto de autenticidad, ligándola a las bandas epigráficas textiles asociadas al tiraz (HOFFMAN, Eva R., 2001, pp. 32-33), y por mostrar un estatus social privilegiado, especialmente en un mundo iletrado (FLUCK, Cäcilia, 2012, p. 183).

78 MUTHESIUS, Anna, 2004, p. 31. Sobre estos aspectos, véase: MUTHESIUS, Anna, 1997, pp. 119-126 y SCHORTA, Regula, 2016, pp. 47-56. 
siglo XIII o en la fabricación de paños de seda conforme a esquemas compositivos orientales, industria ampliamente consolidada hacia 1300 en Lucca, Génova o Venecia. ${ }^{79}$ A dichas muestras cabría añadir algunas manifestaciones excepcionales, en el plano arquitectónico, en el ámbito veneciano, consecuencia de sus intensos contactos comerciales con Oriente ${ }^{80} y$, por supuesto, en la Sicilia normanda.

Con un carácter más secundario cabría citar, fuera de Italia, el ejemplo de ciertos ámbitos regionales en Francia (Rosellón, Auvergne, etc.), donde sería posible documentar la presencia episódica, en el campo arquitectónico, de algunos elementos islámicos; ${ }^{81}$ del Mediterráneo oriental, donde tendría lugar, durante los siglos XII y XIII, el contacto directo de los cruzados con producciones textiles, cerámicas, metálicas o vidrio de Siria y de Anatolia oriental; ${ }^{82}$ del ámbito septentrional europeo, particularmente de aquellos territorios de habla alemana, donde, a partir del siglo XII, se difundiría un modelo del aguamanil zoomorfo basado en tipologías islámicas, aun cuando las vías de influencia entre las producciones occidentales y las orientales no sean fáciles de trazar con precisión; ${ }^{83}$ o el referido interés que, desde siglo XIII, mostrará Occidente por los paños tártaros.

Este modelo, lejos de agotarse, se vio favorecido, en los siglos finales de la Edad Media, por la expansión del consumo suntuario, por unas mejores capacidades técnicas en la producción de bienes, por el referido gusto por el exotismo -impulsado por los nuevos modelos artísticos y de consumo y por las relaciones diplomáticas, que hicieron de lo extraordinario objeto predilecto del regalo entre cortes- o por la configuración de unas más densas redes comerciales, en las que tendrían un papel protagonista las repúblicas maríti- mas italianas. Todos estos factores ayudan a entender el impulso dado en Italia a la creación de un conjunto de industrias locales que adoptarían pautas orientales. Especialmente en Venecia y Florencia, este proceso adquiriría un cierto relieve a partir de la segunda mitad del siglo XIV -incluso antes, en el ámbito textil-, manifestándose de forma clara a largo del siglo XV en diversas facetas, como la representación pictórica de alfombras o textiles en tablas; la fabricación de las laggioni del ámbito ligur; el impulso al vidrio de $\mathrm{Mu}$ rano, que adoptaría patrones sirios; la confección de telas en Lucca, Florencia y Venecia, siguiendo diseños orientales; la realización de encuadernaciones en cuero, imitando tipologías islámicas; o la adquisición de cerámica valenciana o tappeti orientales. ${ }^{84}$

Este gusto por lo oriental debió alcanzar igualmente las cortes septentrionales, al menos, desde el último cuarto del siglo XIV, las cuales orientaron su mirada hacia la península ibérica, mostrando un interés particular por azulejos o baldosas valencianas. ${ }^{85}$ Aunque el ámbito ceremonial fue secundario, sin embargo, al menos, desde fines del siglo XIV, se habría de producir la difusión en Francia o en Borgoña de las danzas conocidas bajo la denominación de morisque, transmitidas tal vez a través de los contactos políticos entre cortes. ${ }^{86}$

En este contexto, no es extraño que cortes peninsulares como la aragonesa o la navarra mostraran una especial atención hacia los ámbitos castellano o valenciano. Así lo sugiere el hecho de que en 1398 diversos fusteros y maestros fueran enviados por Enrique III a Martín I para trabajar en el palacio de la Aljafería de Zaragoza, que en 1404 el rey aragonés solicitara al castellano el envío de cuatro maestros de "almocarves" o que, al año siguiente, dos fusteros toledanos, Gonzalo

\footnotetext{
79 FONTANA, Maria Vittoria, 1995, pp. 297-306, 312; MACK, Rosamond E., 2002, pp. 30-31, 34.

80 HOWARD, Deborah, 1993. Junto al caso de Venecia, cabría sumar para el ámbito italiano algunos ejemplos secundarios en Pisa, Siena o San Gimignano, referidos en GRABAR, Oleg, 2006b, p. 384.

81 GRABAR, Oleg, 2006b, pp. 384-385; GOSS, Vladimir, 1981, p. 19.

82 PARSONS SOUCEK, Priscilla, 1981, pp. 15-16.

83 BARNET, Peter, 2006, pp. 10-12.

84 FONTANA, Maria Vittoria, 1995, pp. 312-314; HESS, Catherine, 2004; CONTADINI, Anna, 1999, pp. 1-60; JACOBY, David, 2010, pp. 77-78; MACK, Rosamond E., 2002; MACK, Rosamond E., 2004; SPALLANZANI, Marco, 2010; DENNY, Walter B., 2007; BAROVIER MENTASTI, Rosa; CARBONI, Stefano, 2007.

85 Diversos ejemplos en TORRES BALBÁS, Leopoldo, 1949, p. 392; SERRA DESFILIS, Amadeo, 2013, p. 43; DEVONSHIRE, R. L., 1935, p. 42; BETTS, Ian M., 2008, pp. 53-69; PÉREZ HIGUERA, Teresa, 1987, p. 26; PARADA LÓPEZ CORSELAS, Manuel, 2017

86 Sobre esta, véase STEFANO, Giuseppe di, 1983.
} 
Ferrando o Fernández y Mahomet, labraran los techos del palacio mayor de Barcelona, habiendo vuelto probablemente, al menos, el primero a Barcelona en 1406;87 que Carlos III de Navarra enviara en 1402 a dos de sus maestros a Segovia, para poder conocer los palacios del rey de Castilla;88 o que en 1400 y 1406 Carlos III encargara azulejos valencianos con destino al palacio de Olite. ${ }^{89}$

En este sentido, el interés por lo islámico que muestran las élites políticas castellanas no sería un caso excepcional dentro del ámbito occidental. Sí constituyó, sin embargo, un aspecto específico de este ámbito castellanoleonés (también parcialmente del aragonés ${ }^{90}$ ), gracias a su carácter fronterizo, por un lado, el privilegiado acceso a la realidad islámica, resultado de la compra, el intercambio diplomático, la captura del botín o el contacto directo; y, por otro lado, la capacidad para dar forma, dentro de este fenómeno global, a manifestaciones como el modelo de palacio mudéjar o las modas a la morisca. Unos aspectos que diferenciarían a este ámbito castellano de las relaciones indirectas y superficiales de otros ámbitos europeos, cuya familiaridad con este modelo islámico quedaba reducida, salvo excepciones, como el caso de Sicilia, a aquellos objetos (alfombras, mobiliario, cerámica) y materiales (azulejos) susceptibles de ser transportados con facilidad, gracias a los intercambios diplomáticos o comerciales. ${ }^{91}$

\section{Bibliografía}

ALEMANY, Joan; BARRAL I ALTET, Xavier; GARCÍA BIOSCA, Joan E. "Introducción". En: Mediterraneum: el esplendor del Mediterráneo medieval, ss. XIII-XV. Barcelona-Madrid: Lunwerg, 2004, pp. 17-25.

ALMAGRO GORBEA, Antonio. Palacios medievales hispanos. Madrid: Real Academia de Bellas Artes de San Fernando, 2008

BAKER, Patricia L. Islamic Textiles. Londres: British Museum Press, 1995.

BARNET, Peter. "Beast of Every Land and Clime. An Introduction to Medieval Aquamanilia". En: Aquamanilia of the Middle Ages, Vessels for Church and Table, New Haven-Londres: Yale University Press, pp. 3-17.
BAROVIER MENTASTI, Rosa; CARBONI, Stefano. "Enameled Glass Between the Eastern Mediterranean and Venice". En: Venice and the Islamic World (828-1797). París: Gallimard, 2007, pp. 252275.

BARRIGÓN, María. "An Exceptional Outfit for an Exceptional King: The Blue Funerary Garments of Alfonso VIII of Castile at Las Huelgas". Viator, 2015, vol. 46, $\mathrm{n}^{\circ}$ 3, pp. 155-172. DOI: 10.1484/ J.VIATOR.5.108329.

BELLO LEÓN, Juan Manuel; HERNÁNDEZ PÉREZ, $\mathrm{M}^{a}$ Beatriz. "Una embajada inglesa a la corte de los Reyes Católicos y su descripción en el Diario de Roger Machado. Año 1489". En la España Medieval, 2003, $n^{\circ} 26$, pp. 167-202.

BETTS, Ian M. "Spanish Tin-glazed Tiles From Woking Palace and Other Sites in South-East England". Surrey Archaeological Collections, 2008, vol. 94, pp. 53-69.

BORRÁS GUALIS, Gonzalo. El arte mudéjar. Teruel: Instituto de Estudios Turolenses, 1990.

BORRÁS GUALÍS, Gonzalo. "A propósito del arte mudéjar: una reflexión sobre el legado andalusí en la cultura española". En: Mirando a Clío: el arte español espejo de su historia: actas del XVIII Congreso del CEHA, Santiago de Compostela, 20-24 de septiembre de 2010. Santiago de Compostela: Universidade de Santiago de Compostela, 2012, pp. 32-57.

BÖSE, Kristin. "Beyond Foreign: Textiles From the Castilian Royal Tombs in Santa María de la Huelgas in Burgos". En: Oriental Silks in Medieval Europe. Riggisberg: Abegg-Stiftung, 2016, pp. 213-230.

BRITT, Karen C. "Roger II of Sicily: Rex, Basileus, and Khalif? Identity, Politics, and Propaganda in the Cappella Palatina". Mediterranean Studies, 2007, vol. 16, pp. 21-45.

BROWNE, Clare et al. (ed.). English Medieval Embroidery. Opus Anglicanum. New Haven-Londres: Yale University Press, 2017.

BURKE, Peter. "Translating Knowledge, Translating Cultures". En: Kultureller Austausch. Bilanz und Perspektiven der Frühneuzeitforschung, ColoniaWeimar-Viena, Böhlau Verlag, 2009, pp. 69-77.

BURKE, Peter. El Renacimiento europeo: centros y periferias. Barcelona: Crítica, 2000.

CACHO BLECUA, José Manuel. "Los problemas del Zifar". En: Libro del caballero Zifar. Códice de París. Barcelona: M. Moleiro Editor, 1995, pp. 55-94.

CAHILL MARRÓN, Emma Luisa. "La influencia de la joyería y orfebrería tardogótica de la corte de los Reyes Católicos en la Inglaterra Tudor". Anales de Historia del Arte, 2014, vol. extra 24, pp. 39-52.

CAÑAS GÁLVEZ, Francisco de Paula. "La cámara de Juan II: vida privada, ceremonia y lujo en la corte de Castilla a mediados del siglo XV". En: Evolu-

\footnotetext{
87 ORTEGO RICO, Pablo, 2016, pp. 467, 741, 811, 820; TORRES BALBÁS, Leopoldo, 1949, p. 328.

88 TORRES BALBÁS, Leopoldo, 1949, pp. 328-329; PÉREZ HIGUERA, Teresa, 1993, p. 84.

89 SERRA DESFILIS, Amadeo, 2013, p. 43.

${ }^{90}$ Son interesantes al respecto los apuntes, que atienden igualmente a la realidad castellana, ofrecidos por SALICRÚ I LLUCH, Roser, 2007, pp. 97-103.

${ }^{11}$ Diversas cuestiones teóricas han sido trazadas al respecto en HOFFMAN, Eva R., 2001, pp. 17-50
} 
ción y estructura de la Casa Real de Castilla. Madrid: Ediciones Polifemo, 2010, t. I, pp. 81-195.

CASTILLO OREJA, Miguel Ángel. "La conservación de un valioso legado. La rehabilitación de los alcázares reales en la política constructiva de los Reyes Católicos". En: Los alcázares reales. Vigencia de los modelos tradicionales en la arquitectura áulica cristiana. Madrid: Fundación BBVA-Antonio Machado Libros, 2001, p. 99-127.

CHUECA GOITIA, Fernando. Historia de la arquitectura española. T. 1. Edad Antigua y Edad Media. Ávila: Fundación Cultural Santa Teresa, 2001.

CÓMEZ RAMOS, Rafael. "Pasadizo o sabat, un tema recurrente de la arquitectura andaluza". Laboratorio de Arte: Revista del Departamento de Historia del Arte, 1988, vol. 1, pp. 13-28.

CONTADINI, Anna. "Artistic Contacts: Current Scholarship and Future Tasks". En: Islam and the Italian Renaissance. Londres: The Warburg Institute, 1999, pp. 1-60.

CÓRDOBA DE LA LLAVE, Ricardo. "Influencias orientales en la artesanía andaluza de la Baja Edad Media". En: Andalucía entre Oriente y Occidente (1236-1492). Actas del V Coloquio Internacional de Historia Medieval de Andalucía. Córdoba: Diputación de Córdoba, 1988, pp. 585-598.

COVARRUBIAS, Sebastián de. Tesoro de la lengua castellana o española. Madrid: Luis Sánchez, 1611.

CUESTA SERRANO, Jaime (ed.). Libro de la miseria de omne. Madrid: Ediciones Cátedra, 2012.

CUTLER, Anthony. "The Parallel Universes of Arab and Byzantine Art (with Special Reference to the Fatimid Era)". En: L'Egypte fatimide: son art et son histoire. París: Presses de l'Université de Paris-Sorbonne, 1999, pp. 635-648.

DENNY, Walter B. "Oriental Carpets and Textiles in Venice". En: Venice and the Islamic World (8281797). París: Gallimard, 2007, pp. 174-191.

DEVONSHIRE, R. L. Quelques influences islamiques sur les arts de l'Europe. El Cairo: R. Schindler, 1935.

DODDS, Jerrilynn D. et al. The Arts of Intimacy. Christians, Jews, and Muslims in the Making of Castilian Culture. New Haven-Londres: Yale University Press, 2008.

DOMÍNGUEZ CASAS, Rafael. "La corte y la imagen real". En: Los Reyes Católicos y la monarquía de España. Madrid: Sociedad Estatal de Conmemoraciones Culturales, 2004, pp. 75-96.

FALLOWS, Noel. Jousting in Medieval and Renaissance Iberia. Woodbridge: Boydell Press, 2010.

FELICIANO, Ma Judith. "Muslim Shrouds for Christian Kings: A Reassessment of Andalusi Textiles in Thirteenth-Century Castilian Life and Ritual". En: Under the Influence: Rethinking the Comparative in Medieval Iberia. Leiden: Brill, 2003, pp. 101-131.

FLUCK, Cäcilia. "Inscribed Textiles", En: Byzantium and Islam: Age of Transition, 7th-9th Century. Nueva York-New Haven-Londres: Metropolitan Museum of Art-Yale University Press, 2012, p. 183.

FONTANA, Maria Vittoria. "The Influence of Islamic Art in Italy". Annali dell'Università degli studi di Napoli "L'Orientale", 1995, vol. 55, n 3, pp. 296319.
FUCHS, Barbara. Una nación exótica. Maurofilia y construcción de España en la temprana Edad Moderna. Madrid: Polifemo, 2011.

GARCÍA ALCÁZAR, Silvia. "Mudejarismo y romanticismo: orígenes del concepto de arte mudéjar". En: XI Simposio Internacional de Mudejarismo. Teruel: Centro de Estudios Mudéjares, 2009, pp. 439-450.

GARCÍA DE SANTA MARÍA, Alvar. Crónica de Juan /I de Castilla. Madrid: Real Academia de la Historia, 1982.

GARCÍA NISTAL, Joaquín. "La incorporación del término mudéjar a la historia de la arquitectura española: un mérito compartido". En: Actas XII Simposio Internacional de mudejarismo: Teruel, 14-16 de septiembre de 2011. Teruel: Centro de Estudios Mudéjares, 2013, pp. 199-211.

GIMÉNEZ, Gilberto. La cultura como identidad y la identidad como cultura. México D.F.: Instituto de Investigaciones Sociales, UNAM, 2003 [en línea] URL: <https://perio.unlp.edu.ar/teorias2/ textos/articulos/gimenez.pdf>.

GÓMEZ GALÁN, José. "El mudéjar como estilo artístico: una valoración historiográfica". Mirabilia: Mediterranean and Transatlantic Approaches to the Culture of the Crown of Aragon, 2017, vol 5, $\mathrm{n}^{\circ} 1$, pp. 89-122 [en línea] URL: <https://www.re vistamirabilia.com/sites/default/files/medtrans/ pdfs/05.04.pdf>.

GONZÁLEZ BARROSO, Josué. "Teoría de los modelos culturales (TMC). Una herramienta de análisis cultural". En: VII Congresso Português de Sociología. Porto, 19 a 22 de Junho de 2012, Oporto: Universidade do Porto, 2012 [en línea] URL: <http://historico.aps.pt/vii_congresso/papers/finais/PAP0410_ed.pdf>.

GONZÁLEZ MARRERO, $\mathrm{M}^{\mathrm{a}}$ del Cristo. La Casa de Isabel la Católica. Espacios domésticos y vida cotidiana. Ávila: Diputación Provincial de Ávila, 2004.

GONZÁLEZ RAMOS, Roberto. "Los hispano-islamismos de Juan Guas. Construcción y revisión de un tópico historiográfico". En: La arquitectura tardogótica castellana entre Europa y América. Madrid: Sílex Ediciones, 2011, pp. 325-337.

GOSS, Vladimir. "Architectural Exchange Between East and West in the Period of the Crusades". En: The Meeting of Two Worlds: The Crusades and the Mediterranean Context. Ann Arbor: The University of Michigan Museum of Art, 1981, pp. 19-21.

GRABAR, Oleg. "Trade with the East and the Influence of Islamic Art in the Luxury Arts in the West". En: Islamic Visual Culture, 1100-1800. Aldershot: Ashgate-Variorum, 2006a, pp. 43-50.

GRABAR, Oleg. "Islamic Architecture and the West: Influences and Parallels". En: Islamic Visual Culture, 1100-1800. Aldershot: Ashgate-Variorum, 2006b, pp. 381-388.

GRASOTTI, Hilda. "El tesoro de Pedro el Cruel". Archivo Español de Arte, 1988, vol. 242, pp. 141152.

HESS, Catherine. The Arts of Fire. Islamic Influences on Glass and Ceramics of the Italian Renaissance. Los Ángeles: The J. Paul Getty Museum, 2004. 
HOFFMAN, Eva R. "Pathsways of Portability: Islamic and Christian Interchange From the Tenth to the Twelfth Century". Art History, 2001, vol. 24, $\mathrm{n}^{\circ}$ 1, pp. 17-50. DOI: 10.1111/1467-8365.00248.

HOWARD, Deborah. Venice \& the East. The Impact of the Islamic World on Venetian Architecture (1100-1500). New Haven-Londres: Yale University Press, 1993.

IRIGOYEN GARCÍA, Javier. "The Game of Canes between the Lusus Troiae and the Albanian Stradioti: Defining Moorish and Classical in the Early Modern Spanish Mediterranean". En: Mediterranean Identities in the Premodern Era. Burlington: Ashgate, 2014, pp. 231-247.

ISAVA, Luis Miguel. "Breve introducción a los artefactos culturales". Estudios. Revista de Investigaciones Literarias y Culturales, 2009, n³4, pp. 439452

JACOBY, David. "Silk Economics and Cross-Cultural Artistic Interaction: Byzantium, the Muslim World, and the Christian West". Dumbarton Oaks Papers, 2004, vol. 58, pp. 197-240. DOI: $10.2307 / 3591386$.

JACOBY, David. "Oriental Silks Go West: A Declining Trade in the Later Middle Ages". En: Islamic Artefacts in the Mediterranean World: Trade, Gift Exchange and Artistic Transfer. Venecia: Marsilio Editori, 2010, pp. 71-88.

JULLIEN, François. La identidad cultural no existe. Barcelona: Taurus, 2017.

KUME, Junco. "El arte mudéjar en la Historia del arte español: en busca de una identidad". En: Imaginarios en conflicto: "lo español" en los siglos XIX y XX: XVIII Jornadas Internacionales de Historia del Arte, celebradas del 14 al 16 de septiembre de 2016, en Madrid. Madrid: Consejo Superior de Investigaciones Científicas, 2017, pp. 345-355

LARREA, Juan José. "Du Tiraz de Cordoue aux montagnes du Nord. Le luxe en milieu rural dans I'Espagne chrétienne du Haut Moyen Âge". En: Objects sous contrainte. Circulation des objects et valeur des choses au Moyen Âge. París: Publications de la Sorbonne, 2013, pp. 43-61.

LÓPEZ GUZMÁN, Rafael. "Los espacios de la monarquía: Granada en los albores del Renacimiento". En: Los alcázares reales. Vigencia de los modelos tradicionales en la arquitectura áulica cristiana. Madrid: Fundación BBVA-Antonio Machado Libros, 2001, pp. 145-166.

MACK, Rosamond E. "El arte italiano y el comercio islámico". En: Mediterraneum: el esplendor del Mediterráneo medieval, ss. XIII-XV. BarcelonaMadrid: Lunwerg, 2004, pp. 321-337.

MACK, Rosamond E. Bazaar to Piazza. Islamic Trade and Italian Art (1300-1600). Berkeley-Los Ángeles-Londres: University of California Press, 2002.

MACKIE, Louise, W. Symbols of Power. Luxury Textiles from Islamic Lands, 7th-21st Century. Cleveland: Cleveland Museum of Art New Haven-Yale University Press, 2015, pp. 10-275.

MÁRQUEZ VILLANUEVA, Francisco. El concepto cultural alfonsí. Barcelona: Edicions Bellaterra, 2004.

MARTÍNEZ CAVIRÓ, Balbina. Mudéjar toledano. Palacios y conventos. Madrid: 1980.
MARTÍNEZ DE AGUIRRE, Javier. "Espiritualidad laica, arquitectura funeraria y hospitalidad en la Península Ibérica en tiempos de Alfonso VIII (11581214)". En: Alfonso VIII y Leonor de Inglaterra: confluencias artísticas en el entorno de 1200. Madrid: Ediciones Complutense, 2017, pp. 447-502.

MARTÍNEZ DE LAGOS FERNÁNDEZ, Eukene. "Un tema iconográfico procedente del arte oriental antiguo en la escultura medieval alavesa: el águila con presa". Sancho el Sabio: Revista de Cultura e Investigación Vasca, 1997, vol. 7, pp. 313-330.

MARTÍNEZ NESPRAL, Fernando. Un juego de espejos: rasgos mudéjares de la arquitectura y el habitar en la España de los siglos XVI-XVII. Buenos Aires: Nobuko, 2007.

MENÉNDEZ PIDAL, Faustino. "Estudio heráldico del almohadón". En: Vestiduras pontificales del arzobispo Rodrigo Ximénez de Rada. S. XIII. Estudio y restauración. Madrid: Ministerio de Cultura, 1994, pp. 28-43.

MENÉNDEZ PIDAL, Faustino. Heráldica de la Casa Real de León y de Castilla (siglos XII-XVI). Madrid: Ediciones Hidalguía, 2011.

MILHOU, Alain. "Desemitización y europeización de la cultura española desde la época de los Reyes Católicos hasta la expulsión de los moriscos". En: La cultura del Renaixement: homenatge al pare Miquel Batllori. Bellaterra: Universitat Autònoma de Barcelona, 1993, pp. 35-60.

MOGOLLÓN CANO-CORTÉS, Pilar. "El arte mudéjar como diálogo y transmisión intercultural transfronteriza". En: Mudéjar. El legado andalusí en la cultura española. Zaragoza: Universidad de Zaragoza, 2010, pp. 265-273.

MÜNZER, Jerónimo. Viaje por España y Portugal. Madrid: Ediciones Polifemo, 2002.

MUTHESIUS, Anna. Byzantine Silk Weaving AD 400 to $A D$ 1200. Viena: Fassbaender, 1997.

MUTHESIUS, Anna. Studies in Silk in Byzantium. Londres: The Pindar Press, 2004.

NAVARRO ESPINACH, Germán. El despegue de la industria sedera en la Valencia del siglo XV. Valencia: Generalitat Valenciana, 1992.

NAVARRO ESPINACH, Germán. Los orígenes de la sedería valenciana (siglos XV-XVI). Valencia: Ayuntamiento de Valencia, 1999.

NEBRIJA, Antonio de. Vocabulario español-latino. Salamanca: Impresor de la Gramática castellana, 1495.

NOGALES RINCÓN, David. La representación religiosa de la realeza castellano-leonesa: la Capilla Real (1252-1504). Madrid: Universidad Complutense, 2010 [en línea] URL: <http://eprints.ucm. es/9819/1/T31467.pdf>.

NOGALES RINCÓN, David. "Un año en la corte de Enrique III de Castilla (1397-1398)". En la España Medieval, 2014, vol. 37, pp. 85-130.

NOGALES RINCÓN, David. "El color negro. Luto y magnificencia en la Corona de Castilla (siglos XIIIXV)". Medievalismo, 2016, vol. 26, pp. 221-245.

NOGALES RINCÓN, David. "Representación animal y relaciones de poder en la península ibérica durante la Edad Media". En: Animales y racionales en la historia de España. Madrid: Sílex Ediciones, 2017, pp. 253-290.

NOGALES RINCÓN, David. "La monta a la gineta y sus proyecciones caballerescas: de la frontera de 
los moros a la corte real de Castilla (siglos XIVXV)", 2019, en preparación.

ORTEGO RICO, Pablo. Documentos de Enrique III. Fondo Mercedes Gaibrois de Ballesteros. Madrid: Real Academia de la Historia, 2016 [en línea] URL: <http://www.rah.es/wp-content/uploads/2016/11/Documentos_Enrique-III_M.-Gaibrois.pdf>.

PARADA LÓPEZ CORSELAS, Manuel. El viaje de Jan van Eyck de Flandes a Granada (1428-1429). Madrid: La Ergástula, 2017.

PARSONS SOUCEK, Priscilla. "Artistic Exchange in the Mediterranean Context". En: The Meeting of Two Worlds: The Crusades and the Mediterranean Context. Ann Arbor: The University of Michigan Museum of Art, 1981, pp. 15-16.

PASSINI, Jean. "El portal de las casas principales de los Oter de Lobos (Tordelobos): Aportaciones de los textos". En: La ciudad medieval de Toledo: historia, arqueología y rehabilitación de la casa. El edificio Madre de Dios. Cuenca: Universidad de Castilla-La Mancha, 2007 pp. 369-379.

PAULINO MONTERO, Elena. "¿Identidad religiosa e identidad artística? Las yeserías de Medina de Pomar y el papel mediador del ornamento". En: Identidades cuestionadas. Coexistencia y conflictos interreligiosos en el Mediterráneo. Valencia: Universitat de València, 2016, pp. 395-408.

PAULINO MONTERO, Elena. "Architecture and Artistic Practices in Fourteenth Century Castile. The Visual Memory of Alfonso XI and Pedro I Under the First Trastamaran Kings". La Corónica, 2017, vol. 45, n², pp. 133-163.

PÉREZ HIGUERA, Teresa. Mudejarismo en la Baja Edad Media. Madrid: La Muralla, 1987.

PÉREZ HIGUERA, Teresa. Arquitectura mudéjar en Castilla y León. Valladolid: Junta de Castilla y León, 1993.

PÉREZ HIGUERA, Teresa. Objetos e imágenes de alÁndalus. Madrid-Barcelona: Instituto de Cooperación con el Mundo Árabe-Lunwerg, 1994.

PÉREZ HIGUERA, Teresa. "El mudéjar, una opción artística en la corte de Castilla y León". En: Historia del arte de Castilla y León. Tomo IV. Arte mudéjar. Valladolid: Ámbito, 1996, pp. 129-222.

PRADILLO Y ESTEBAN, Pedro José. "El alcázar real de Guadalajara. Un castillo ignorado". Castillos de España, 2003, vol. 129, pp. 3-19.

RALLO GRUSS, Carmen. Aportaciones a la técnica $y$ estilística de la pintura mural en Castilla a final de la Edad Media: tradición e influencia islámica. Madrid: Universidad Complutense de Madrid, 2003 [en línea] URL: <http://eprints.ucm. es/2521>.

RESENDE, Garcia de. "A entrada del rey Dom Manoel em Castella". En: Crónica de D. João /l e miscelánea. Lisboa: Imprensa Nacional-Casa da Moeda, 1973, pp. 297-318.

RODRÍGUEZ MORENO, Concepción. El palacio de Pedro I en los Reales Alcázares de Sevilla. SeviIla: Editorial Universidad de Sevilla-Fundación Focus-Abengoa, 2015.

ROSELL, Cayetano (ed.), Crónicas de los reyes de Castilla. Madrid: Atlas, 1953.

RUIZ SOUZA, Juan Carlos. "Castilla y al-Ándalus. Arquitecturas aljamiadas y otros grados de asimilación". Anuario del Departamento de Historia y Teoría del Arte, 2004, vol. 16, pp. 17-44.
RUIZ SOUZA, Juan Carlos. "Al-Ándalus y cultura visual: Santa María la Real de las Huelgas y Santa Clara de Tordesillas. Dos hitos en la asimilación de al-Ándalus en la reinteriorización de la Corona de Castilla". En: El legado de al-Ándalus. El arte andalusí en los reinos de León y Castilla durante la Edad Media. Valladolid: Fundación de Patrimonio Histórico de Castilla y León, 2007, pp. 205-242.

RUIZ SOUZA, Juan Carlos. "Le style mudéjar en architecture cent cinquante ans après". Perspective, 2009, $\mathrm{n}^{\circ} 2$, pp. 277-286.

RUIZ SOUZA, Juan Carlos. "Construcción y búsqueda de un estilo nacional. El estilo mudéjar ciento cincuenta años después". En: La invención del estilo Hispano-Magrebí: presente y futuros del pasado. Barcelona: Anthropos, 2010, pp. 177-199.

RUIZ SOUZA, Juan Carlos. "Castilla y la libertad de las artes en el siglo XV. La aceptación de la herencia de al-Ándalus: de la realidad material a los fundamentos teóricos". Anales de Historia del Arte, 2012, vol. extra 1, pp. 123-161.

RUIZ SOUZA, Juan Carlos. "Los espacios palatinos del rey en las cortes de Castilla y Granada. Los mensajes más allá de las formas". Anales de Historia del Arte, 2013, vol. extra 2, pp. 305-331.

RUIZ SOUZA, Juan Carlos: "El rey y sus espacios en palacio en la Corona de Castilla y León en la $\mathrm{Ba}$ ja Edad Media". En: Arquitectura tardogótica en la Corona de Castilla. Trayectorias e intercambios. Santander-Sevilla: Editorial de la Universidad de Cantabria-Universidad de Sevilla, 2014, pp. 35-54.

RUIZ SOUZA, Juan Carlos. "Los estilos nacionales y sus discursos identitarios: el denominado estilo mudéjar". En: La Historia del Arte en España: devenir, discursos y propuestas. Madrid: Ediciones Polifemo, 2016, pp. 197-216.

SACHSENMAIER, Dominic. Global Perspectives on Global History: Theories and Approaches in a Connected World. Cambridge: Cambridge University Press, 2011.

SALICRÚ I LLUCH, Roser. "La diplomacia y la embajadas como expresión de los contactos interculturales entre cristianos y musulmanes en el Mediterráneo occidental durante la Baja Edad Media". Estudios de Historia de España, 2007, n 9 , pp. 77-106.

SCHORTA, Regula. "Central Asian Silks in the East and West During the Second Half of the First Millenium". En: Oriental Silks in Medieval Europe. Riggisberg: Abegg-Stiftung, 2016, pp. 47-63.

SERRA DESFILIS, Amadeo. "Convivencia, asimilación y rechazo: el arte islámico en el Reino de Valencia desde la conquista cristiana hasta las Germanías (circa 1230-circa 1520)". En: Memoria y Significado. Uso y recepción de los vestigios del pasado. Valencia: Universitat de València, 2013, pp. 33-60.

SILVA SANTA-CRUZ, Noelia. "Maurofilia y mudejarismo en época de Isabel la Católica". En: Isabel la Católica. La magnificencia de un reinado. Madrid-Valladolid: Sociedad Estatal de Conmemoraciones Culturales-Junta de Castilla y León, 2004, pp. 141-154.

SILVA SANTA-CRUZ, Noelia. "La Corte de los Reyes Católicos y el reino nazarí. Permeabilidad cultu- 
ral e intercambios artísticos". En: El arte en la Corte de los Reyes Católicos. Rutas artísticas a principios de la Edad Moderna. Madrid: Fundación Carlos de Amberes, 2005, pp. 267-286.

SILVA SANTA-CRUZ, Noelia. "El combate de animales en el arte islámico". Revista Digital de Iconografía Medieval, 2014, vol. 11, pp. 13-22 [en línea] URL: <https://www.ucm.es/bdiconografiamedieval/numero-11>.

SPALLANZANI, Marco. "Tappeti orientali a Firenze nel Rinascimento". En: Islamic Artefacts in the Mediterranean World: Trade, Gift Exchange and Artistic Transfer. Venecia: Marsilio Editori, 2010, pp. 89-104.

STEFANO, Giuseppe di. "La morisque en France". Le Moyen français, 1983, vols. 8-9, pp. 264-290.

THOMAS, Thelma K. "Ornaments of excellence from the miserable gains of commerce: Luxury Art and Byzantine Culture". En: Byzantium and Islam: Age of Transition, 7th-9th Century. Nueva York-New Haven-Londres: Metropolitan Museum of Art-Yale University Press, 2012, pp. 124-133.

TOLLEY, Thomas. "Eleanor of Castile and the Spanish Style in England". En: England in the Thirteenth Century: Proceedings of the 1989 Harlaxton Symposium. Stamford: Watkins, 1991, pp. 167-192.
TORRES BALBÁS, Leopoldo. "Arte mudéjar". En: Arte almohade. Arte nazarí. Arte mudéjar. Madrid: Editorial Plus Ultra, 1949, pp. 237-409.

TORRES BALBÁS, Leopoldo. “El ambiente mudéjar en torno a la Reina Católica y el arte hispanomusulmán en España y Berbería durante su reinado". En: Curso de conferencias sobre la política africana de los Reyes Católicos. Tomo II. Madrid: Instituto de Estudios Africanos, 1951, pp. 81-125.

URQUÍZAR HERRERA, Antonio. "La caracterización política del concepto mudéjar en España durante el siglo XIX". Espacio, Tiempo y Forma. Serie VII. Historia del Arte, 2009-2010, nos. 22-23, pp. 201216.

URQUÍZAR HERRERA, Antonio. Admiration and Awe. Morisco Buildings and Identity Negotiations in Early Modern Spanish Historiography. Oxford: Oxford University Press, 2017.

WERNER, Michael; ZIMMERMANN, Bénédicte. "Penser I'histoire croisée: entre empirie et réflexivité". Annales. Histoire, Sciences Sociales, 2003, vol. 58, n 1, pp. 7-36.

WOODFIN, Warren T. "Presents Given and Presence Subverted: The Cunegunda Chormantel in Bamberg and the Ideology of Byzantine Textiles". Gesta, 2008, vol. 47, n 1, pp. 33-50. DOI: $10.2307 / 20648959$. 